\title{
Temperature Rise of the Mask-Resist Assembly during LIGA Exposure
}

Aili Ting

Prepared by

Sandia National Laboratories

Albuquerque, New Mexico 87185 and Livermore, California 94550

Sandia is a multiprogram laborator/ operated by Sandia Cornoration,

a Lockheed Martin Company, for the United Stetios Decartment of Energy's

National Nuclear Security Adminizusation inder Contra ct DE-AC04-94-AL85000.

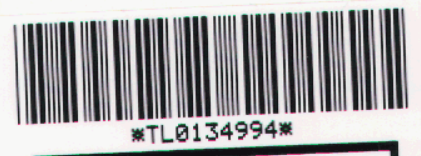

SANDIA NATIONAL

LABORATORIES

Approved for public release; further dissemination unlimited.

\section{(11) Sandia National Laboratories}


Issued by Sandia National Laboratories, operated for the United States Department of Energy by Sandia Corporation.

NOTICE: This report was prepared as an account of work sponsored by an agency of the United States Government. Neither the United States Government, nor any agency thereof, nor any of their employees, nor any of their contractors, subcontractors, or their employees, make any warranty, express or implied, or assume any legal liability or responsibility for the accuracy, completeness, or usefulness of any information, apparatus, product, or process disclosed, or represent that its use would not infringe privately owned rights. Reference herein to any specific commercial product, process, or service by trade name, trademark, manufacturer, or otherwise, does not necessarily constitute or imply its endorsement, recommendation, or favoring by the United States Government, any agency thereof, or any of their contractors or subcontractors. The views and opinions expressed herein do not necessarily state or reflect those of the United States Government, any agency thereof, or any of their contractors.

Printed in the United States of America. This report has been reproduced directly from the best available copy.

Available to DOE and DOE contractors from

U.S. Department of Energy

Office of Scientific and Technical Information

P.O. Box 62

Oak Ridge, TN 37831

Telephone: $\quad$ (865) 576-8401

Facsimile: $\quad$ (865) 576-5728

E-Mail: $\quad$ reports@adonis.osti.gov

Online ordering: http://www.doe.gov/bridge

Available to the public from

U.S. Department of Commerce

National Technical Information Service

5285 Port Royal Rd

Springfield, VA 22161

Telephone: $\quad$ (800) 553-6847

Facsimile: (703) 605-6900

E-Mail: $\quad$ orders@ntis.fedworld.gov

Online order: $\quad$ http://www.ntis.gov/help/ordermethods.asp?loc=7-4-0\#online 
SAND2004-5446

Unlimited Release

Printed November 2004

\section{Temperature Rise of the Mask-Resist Assembly during LIGA Exposure}

\author{
Aili Ting \\ Fluid and Thermal Science Department \\ Sandia National Laboratories \\ Livermore, California 94551-0969 MS 9042
}

\author{
LIBRARY DOCUMENT \\ DO NOT DESTROY \\ RETURN TO \\ LIBRARY VAULT
}

\section{Abstract}

Deep X-ray lithography on PMMA resist is used in the LIGA process. The resist is exposed to synchrotron X-rays through a patterned mask and then is developed in a liquid developer to make high aspect ratio microstructures. The limitations in dimensional accuracies of the LIGA generated microstructure originate from many sources, including synchrotron and Xray physics, thermal and mechanical properties of mask and resist, and from the kinetics of the developer. This work addresses the thermal analysis and temperature rise of the maskresist assembly during exposure in air at the Advanced Light Source (ALS) synchrotron. The concern is that dimensional errors generated at the mask and the resist due to thermal expansion will lower the accuracy of the lithography.

We have developed a three-dimensional finite-element model of the mask and resist assembly that includes a mask with absorber, a resist with substrate, three metal holders, and a watercooling block. We employed the LIGA exposure-development software LEX-D to calculate volumetric heat sources generated in the assembly by X-ray absorption and the commercial software ABAQUS to calculate heat transfer including thermal conduction inside the assembly, natural and forced convection, and thermal radiation at assembly outer and/or inner surfaces.

The calculations of assembly maximum temperature have been compared with temperature measurements conducted at ALS. In some of these experiments, additional cooling of the assembly was produced by forced nitrogen flow ("nitrogen jets") directed at the mask surface. The temperature rise in the silicon mask and the mask holder comes directly from the X-ray absorption, but nitrogen jets carry away a significant portion of heat energy from the mask surface, while natural convection carries away negligibly small amounts energy from the holder. The temperature rise in PMMA resist is mainly from heat conducted from the silicon substrate backward to the resist and from the inner cavity air forward to the resist, while the $\mathrm{X}$-ray absorption is only secondary. Therefore, reduction of heat flow conducted from both substrate and cavity air to the resist is essential. An improved water-cooling block is expected to carry away most heat energy along the main heat conductive path, leaving the resist at a favorable working temperature. 


\section{Acknowledgments}

The present work was funded by LIGA Technology Maturation Program. Sandia is a multiprogram laboratory operated by Sandia Corporation, a Lockheed Martin Company, for the United States Department of Energy under contract DE-AC04-94AL85000. The author would like to thank Mike Malinowski and Cheryl Hauck for their help in providing information for the ALS 3.3.2 beam line and performing temperature measurements. The author also would like to thank Greg Evans and Mike Malinowski for their critical review of the manuscript. 


\section{Contents}

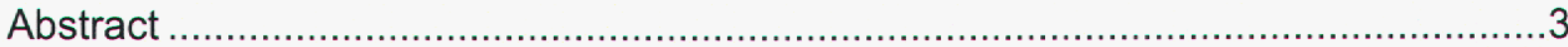

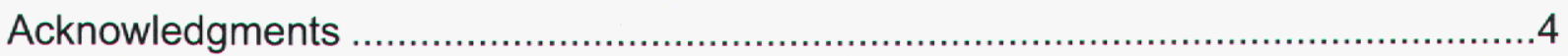

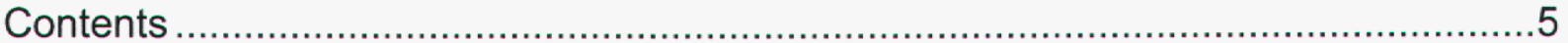

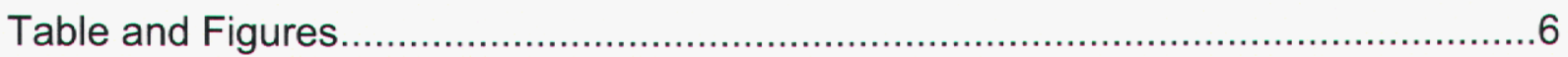

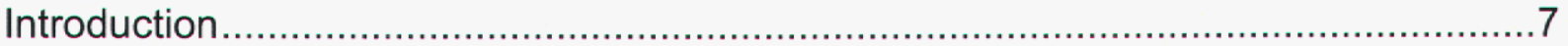

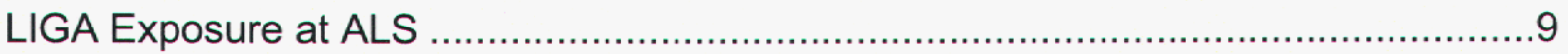

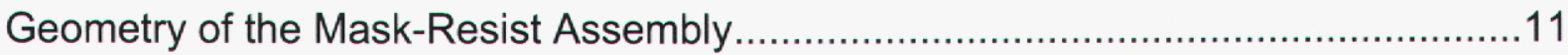

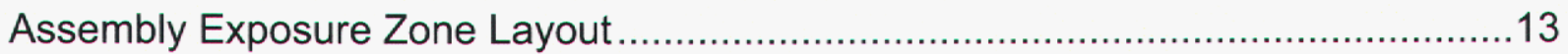

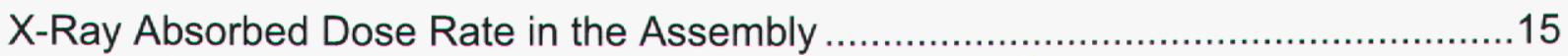

Thermal Analysis of the LIGA Resist Exposure ...................................................17

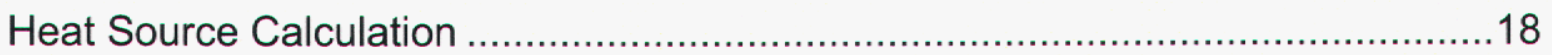

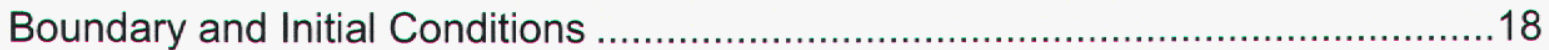

Forced and Natural Convective Heat Transfer..................................................19

Results of Absorption Dose and Time Integration Heat Fluxes ..............................21

Energy Absorption in the Mask-Resist Assembly Components ............................21

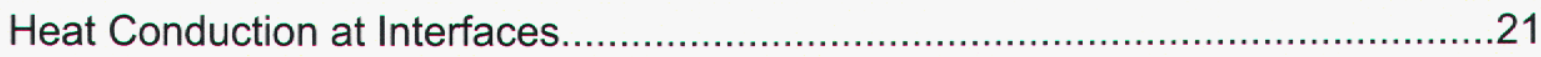

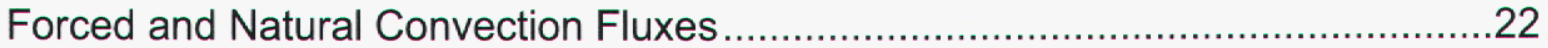

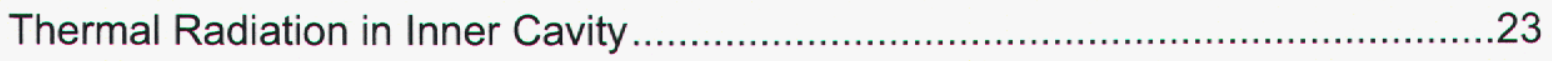

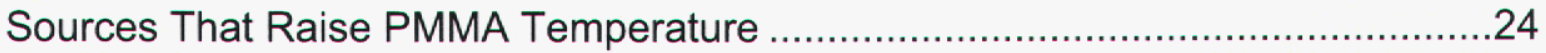

Results of Maximum Temperature Examples .......................................................25

Comparison with Temperature Measurements ....................................................29

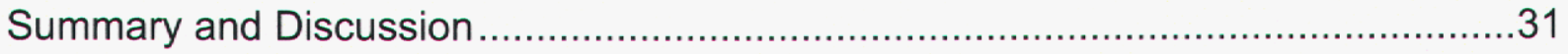

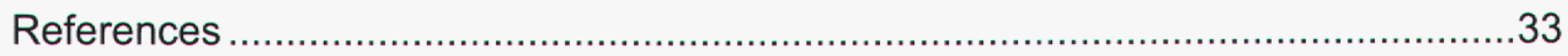

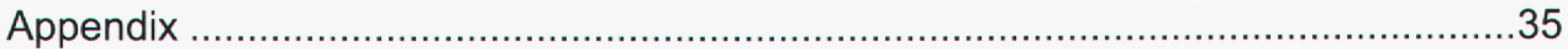

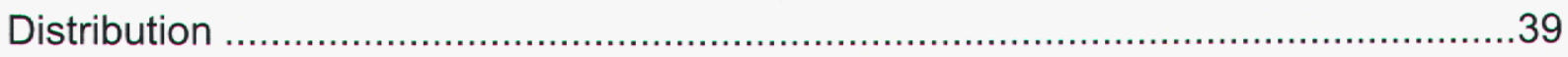




\section{Table and Figures}

Table 1. Component material, geometry, and interfacial connection ........................12

Table 2. Absorbed dose rate $\left[\mathrm{W} / \mathrm{m}^{3}\right]$ of materials in each zone ................................ 15

Table 3. Thermo-Physical Properties of Materials ................................................... 18

Figure 1. LIGA mask-resist assembly and its cross-section view ............................ 7

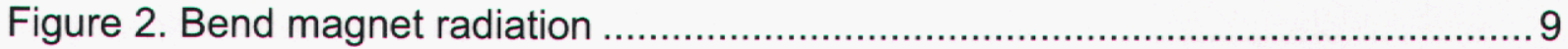

Figure 3. ALS 3.3.2 beam line LIGA hutch sketch ................................................ 10

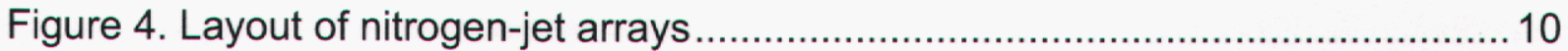

Figure 5. LIGA mask-resist assembly (seven components) …............................. 11

Figure 6. Top view of the assembly scanned region................................................ 13

Figure 7. Cross-section view of the exposure zones (not to scale) ......................... 14

Figure 8. Cross-section of the mask-resist assembly ............................................. 17

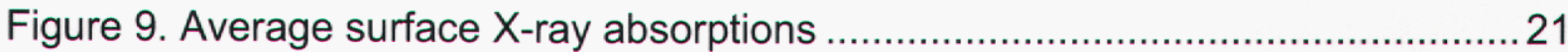

Figure 10. Cumulative time integrated interfacial heat fluxes ...................................2 22

Figure 11. Cumulative convective heat fluxes at sample top surfaces ......................23

Figure 12. Cumulative time integrated net thermal radiation fluxes at cavity

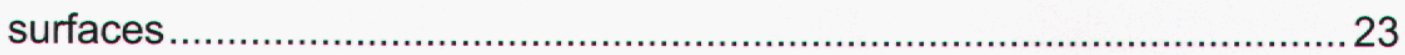

Figure 13. Absorption and cumulative heat fluxes to PMMA …...............................24

Figure 14. Time history of maximum temperature (case 1) …...................................2 25

Figure 15. Time history of maximum temperature (worse case in case 1) ...............26

Figure 16. Time history of maximum temperature (case 2) ..................................2 27

Figure 17. Thermal couples locations on the assembly ............................................29

Figure 18. Assembly temperature measurements .................................................... 30

Figure 19. Heat transfer paths in the assembly .................................................... 32

Figure A1. ALS beam line diagram-clock diagram ................................................... 35

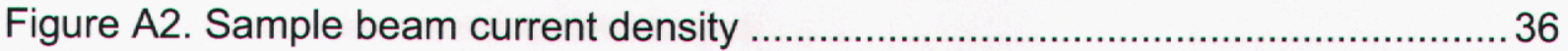

Figure A3. A Numerical fit of the measured Gaussian profile from synchrotron

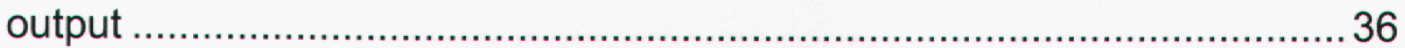

Figure A4. Gaussian train in wafer scanning time history graph..............................37 


\section{Introduction}

Deep X-ray lithography on PMMA resist is used in the LIGA process. The resist is exposed to synchrotron X-rays through a patterned mask and then is developed in a liquid developer to make high aspect ratio microstructure molds. The limitations in dimensional accuracies of the LIGA generated microstructure originate from many sources, including synchrotron and Xray physics, thermal and mechanical properties of mask and resist, and from the kinetics of the developer. Since high temperatures can generate dimensional errors due to thermal expansion on both the mask and resist and thus lower the accuracy of lithography, this work discusses only the thermal behavior and temperature rise of the mask-resist assembly during exposure, and focuses on the time-temperature behaviors of the mask and resist.
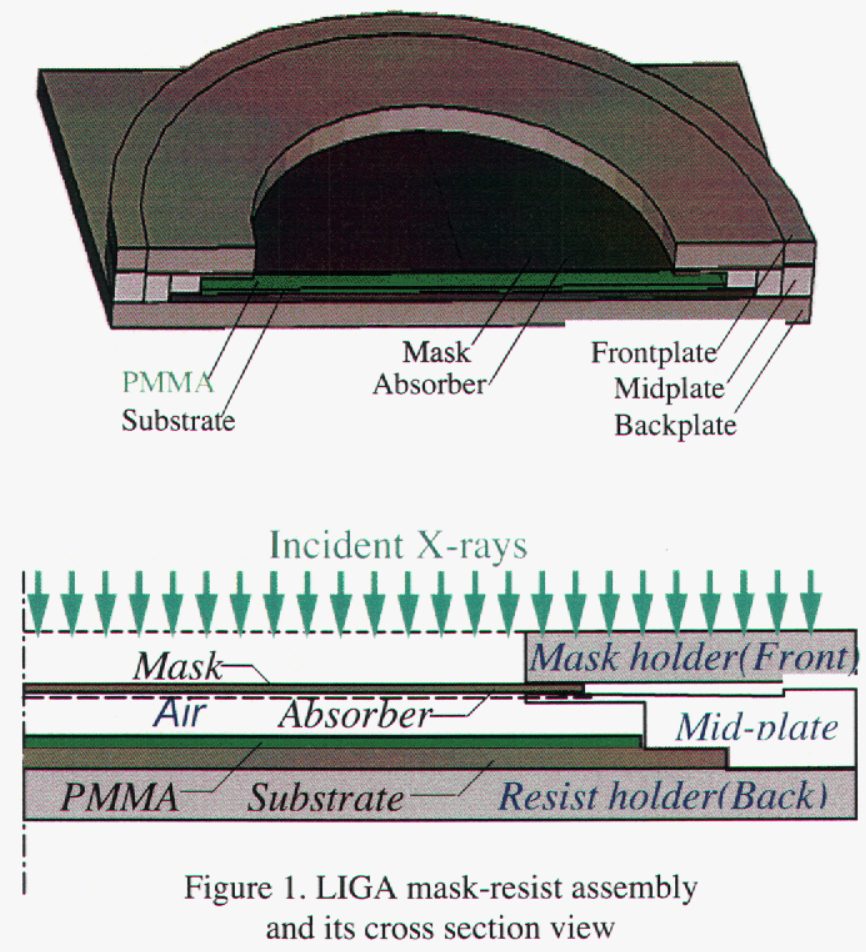

The mask-wafer assembly consists of a silicon mask plate, a gold absorber, a PMMA resist, a silicon substrate, three metal plate holders (aluminum front and back plates, stainless steel mid plate), as shown in Figure 1, and a water-cooling block attached to the back plate (not shown in the figure). The front plate is the mask holder, and the back plate is the resist holder. The assembly has eight contact interfaces and one inner cavity of air enclosed by five materials. Two nitrogen jet arrays are used to cool the exposed mask area during the $\mathrm{X}$-ray exposure.

The assembly temperature rise is due to X-ray absorption that generates heat. Due to the gradual decrease of $\mathrm{X}$-ray intensity along its transmitted path and the different absorption coefficients, the mask absorbs about 50 times the X-ray dose that the resist absorbs.

Therefore, it seems that the mask plate would have high temperature rise while the resist may have negligible temperature rise considering the higher specific heat of PMMA. However, the heat transfer can exchange and redistribute the heat energy among the assembly components. 
In addition, the three metal plates could become the important thermal conduction paths between the components and are also exposed to either incident or transmitted X-rays. Therefore, the thermal analysis needs to be performed on the whole assembly in order to quantitatively determine temperature profiles in the assembly.

We completed a thermal analysis on a LIGA mask-wafer assembly exposed in air at the beam line 3.3.2 of ALS (Advanced Light Source of Lawrence Berkeley Laboratory) by developing a three-dimensional finite-element model of the assembly. We employed the LIGA exposuredevelopment software LEX-D (V7.54)[1] to calculate the X-ray absorption dose rate in the assembly, which serves as a volumetric heat source in the assembly. We used the commercial software ABAQUS (V6.3)[2] to calculate the heat transfer due to this heat source, including heat fluxes inside and across the material interfaces due to thermal conduction, heat loss at the assembly outer surface due to natural and forced convection, and thermal radiation, as well as heat exchange in the inner cavity due to thermal radiation. The results were compared with the experimental temperature measurements for the mask-resist assemblies under X-ray exposure at the ALS 3.3.2 beam line [3]. 


\section{LIGA Exposure at ALS}

The X-ray exposure of mask-resist assembly samples is conducted at ALS Beam line 3.3.2, a bend magnet beam line. In the ALS, electrons circulate in the storage ring and radiate photons, as sketched in Figure 2. Beam energy is typically $1.894 \mathrm{GeV}$. The emitted photon fan has $7 \mathrm{mrad}$ of horizontal angle, so at a beam length distance of $18.1 \mathrm{~m}$, the beam window is $10.94 \mathrm{~cm}$ wide (horizontal acceptance) and $1.16 \mathrm{~cm}$ high. The vertical output power profile from the beam is Gaussian and the total power output is $38.26 \mathrm{~mW} / \mathrm{mr} / \mathrm{mA}$ with photon energy range from 1 to $20 \mathrm{keV}$.

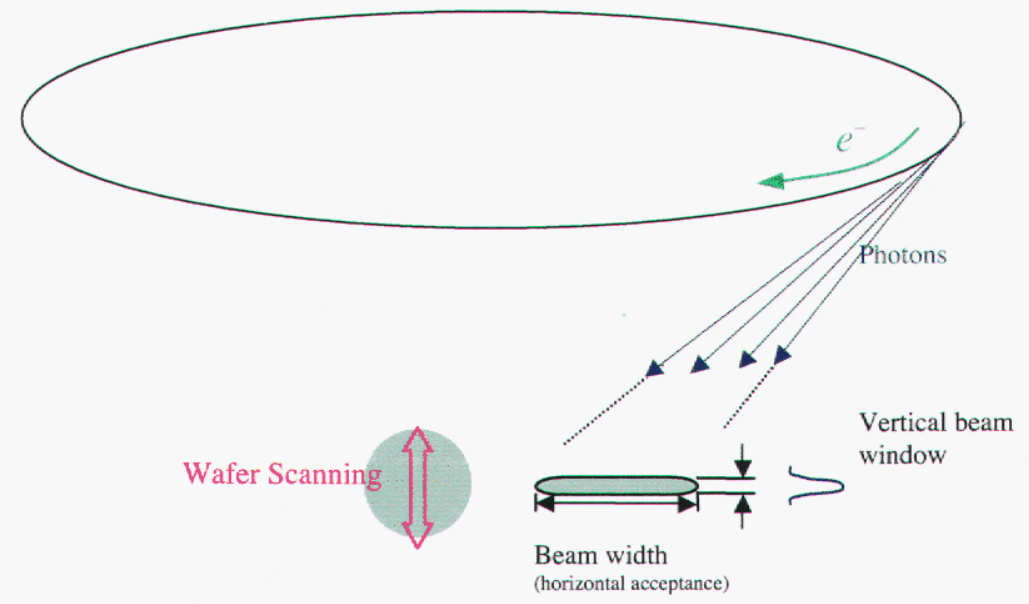

Figure 2. Bend magnet radiation (Electrons move along the storage ring orbit and emit photons).

The average operation beam current density is about $280 \mathrm{~mA}$, from a periodic pattern, i.e., beam current decreases from $400 \mathrm{~mA}$ down to $180 \mathrm{~mA}$ in 8 hours. More details can be found in the Appendix.

The X-ray scanner for the 3.3.2 beam line of ALS is installed in a hutch with dimensions of $2.34 \times 1.75 \times 2.44 \mathrm{~m}^{3}\left(92 \times 69 \times 96 \mathrm{in}^{3}\right)$, as shown in Figure 3. Two 127- $\mu \mathrm{m}$ thick, fixed beryllium windows are located in the beam line, and an aluminum filter $(5.6 \mu \mathrm{m})$ at the beam tube exit. The assembly is sitting on a linear stage that scans up and down vertically in front of the beam window, standing at a distance about $9 \mathrm{~cm}$ from the filter. The scanner sits on a granite table, and a ceiling fan (not shown) is hanging above. Both upper inlet and outlet of water-cooling block ("cube sample holder") are connected to tubes extended outside (not shown). Two nitrogen jet arrays sketched in Figure 4, impinge on the mask surface. The jets come from 28 holes (about $1 / 16$ " in diameter) on two parallel tubes located above and below the aluminum filter to cool the mask. A typical scan length of $8.2 \mathrm{~cm}$ is adopted in the modeling, which, together with the $10.94 \mathrm{~cm}$ beam width, covers a $10.94 \mathrm{X} 8.2 \mathrm{~cm}^{2}$ exposure surface area. In this case, the scanning period is $11.49 \mathrm{~s}$ including the time to turn around, and the uniform scan speed is about $1.5 \mathrm{~cm} / \mathrm{s}$ [4]. 


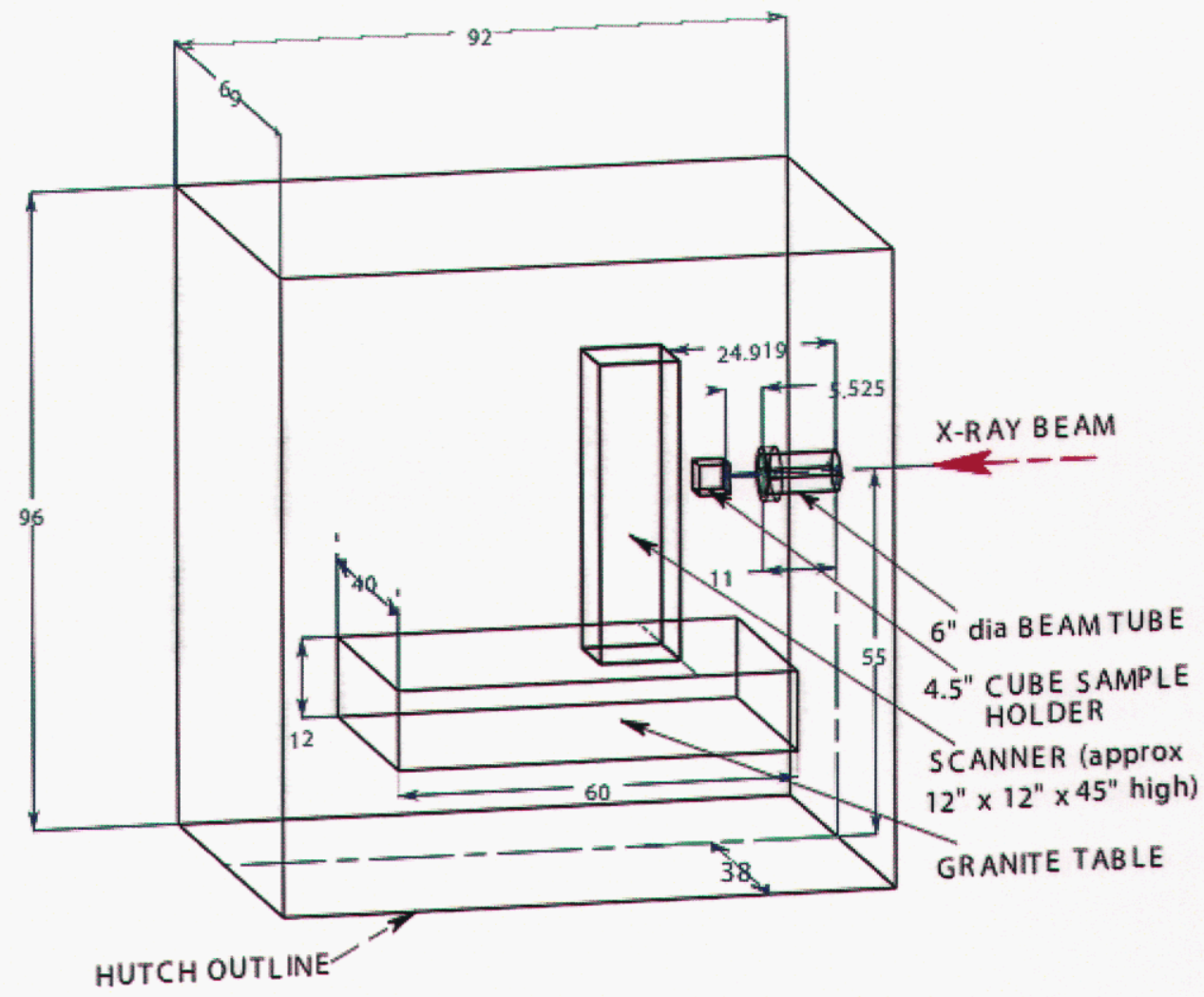

Figure 3. ALS 3.3.2 Beam line LIGA hutch sketch (all dimensions in inches)

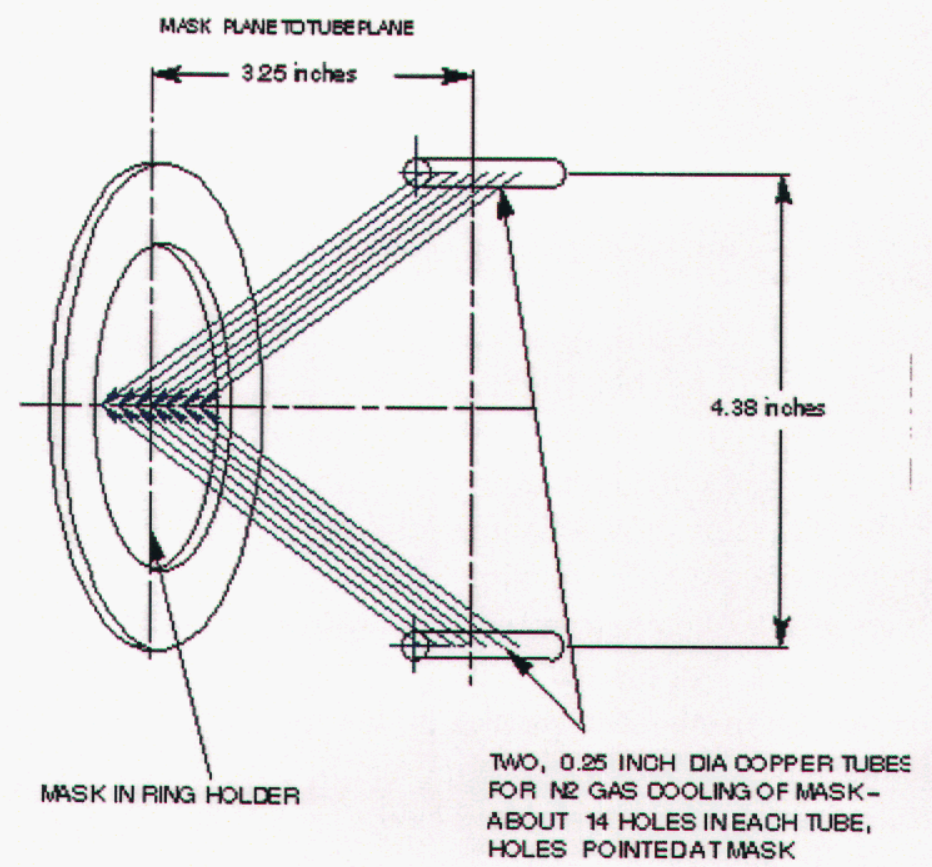

Figure 4. Layout of nitrogen-jet arrays 


\section{Geometry of the Mask-Resist Assembly}

Figure 5 is a sketch of the assembly, its seven pieces, and the cross section view. For numerical simplicity, the half exposure and half masked pattern are assumed for the mask absorber, and the O-rings and screws connected those pieces are not included in the simulation, since we are mostly interested in the maximum temperature instead of local temperature distribution.
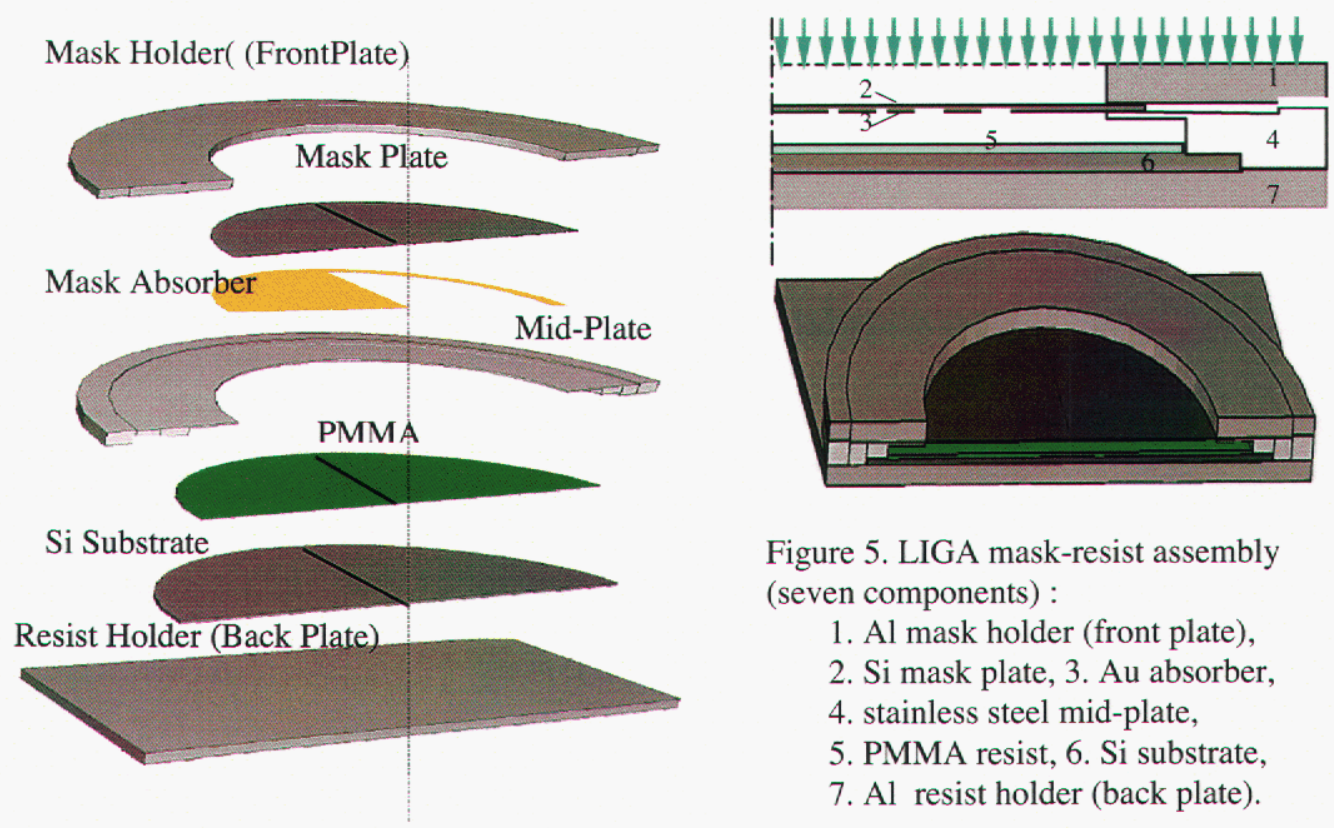

Figure 5. LIGA mask-resist assembly (seven components) :

1. Al mask holder (front plate),

2. Si mask plate, 3. Au absorber,

4. stainless steel mid-plate,

5. PMMA resist, 6 . Si substrate,

7. $\mathrm{Al}$ resist holder (back plate).

Seven contact interfaces and an inner cavity can be identified in the cross section view. The two unique interfaces are 1) the interface between silicon mask and gold absorber where gold absorber is electrodeposited to silicon mask plate, 2) the interface between PMMA and silicon substrate where PMMA is attached to the substrate. The three metal plates-aluminum mask holder (front plate), stainless steel mid-plate, and aluminum resist holder (back plate)-do not have contact with PMMA, but do have contacts with all other components: the outer edge of gold absorber touches the mid-plate front; the silicon mask plate is pressed on with an O-ring in the mask holder back; the silicon substrate is also pressed on with an O-ring in the midplate back; the silicon substrate is in full contact with the resist holder; the back of mid-plate touches the resist holder; the resist holder is in full contact with the water-cooling block(not shown here). The inner cavity is bounded below by the resist and above by the absorber (masked region) and mask plate (open region), and surrounded by the mid-plate. Eight screws (0.096" dia) connect the three holders circumferentially at their outer edges. 
Table 1 lists the material, geometry and interface of each component. Here, air and water are also listed because they are also included in the model.

Table1. Component material, geometry, and interfacial connection

\begin{tabular}{|c|c|c|c|c|}
\hline & Material & Thickness & Diameter & Interfaces \\
\hline $\begin{array}{l}\text { Mask Holder } \\
\text { (Front Plate) }\end{array}$ & $\mathrm{Al}$ & $\begin{array}{l}3175 \mu \mathrm{m} \\
(0.125 ”)\end{array}$ & $\begin{aligned} \mathrm{d} 1= & 6.858 \mathrm{~cm} \\
& \left(2.7^{\prime \prime}\right) \\
\mathrm{d} 2= & 11.43 \mathrm{~cm} \\
& \left(4.5^{\prime \prime}\right)\end{aligned}$ & $\begin{array}{c}\mathrm{Si} \\
(\mathrm{O} \text { ring })\end{array}$ \\
\hline Mask Plate & $\mathrm{Si}$ & $\begin{array}{c}100 \mu \mathrm{m} \\
(0.003937 ”)\end{array}$ & $\begin{array}{l}7.62 \mathrm{~cm} \\
(3 ")\end{array}$ & $\begin{array}{c}\text { Front Plate (O ring), } \\
\text { Au, Cavity Air }\end{array}$ \\
\hline Mask Absorber & $\mathrm{Au}$ & $\begin{array}{c}35 \mu \mathrm{m} \\
(0.00137795 ")\end{array}$ & $\begin{array}{c}7.62 \mathrm{~cm} \\
\left(3^{\prime \prime}\right)\end{array}$ & $\begin{array}{l}\text { SS, Cavity air, } \\
\text { electrodeposited on } \\
\text { Si }\end{array}$ \\
\hline Mid Plate & $\begin{array}{l}\text { Stainless Steel } \\
\text { (SS) }\end{array}$ & $\begin{array}{c}4 \text { thicknesses } \\
\text { Max } 3911.6 \mu \mathrm{m} \\
(0.154 ")\end{array}$ & $\begin{aligned} \mathrm{d} 1= & 6.858 \mathrm{~cm} \\
& \left(2.7^{\prime \prime}\right) \\
\mathrm{d} 2= & 11.43 \mathrm{~cm} \\
& \left(4.5^{\prime \prime}\right)\end{aligned}$ & $\begin{array}{c}\text { Au, Cavity air, } \\
\text { Substrate (O ring), } \\
\text { Back Plate }\end{array}$ \\
\hline Resist & PMMA & $\begin{array}{l}635 \mu \mathrm{m} \\
(0.025 ")\end{array}$ & $\begin{array}{l}8.55 \mathrm{~cm} \\
\left(3.366^{\prime \prime}\right)\end{array}$ & $\begin{array}{l}\text { Cavity air, } \\
\text { Adhered on } \\
\text { Substrate }\end{array}$ \\
\hline Substrate & $\mathrm{Si}$ & $\begin{array}{c}1066.8 \mu \mathrm{m} \\
(0.042 ")\end{array}$ & $\begin{array}{l}9.545 \mathrm{~cm} \\
\left(3.758^{\prime \prime}\right)\end{array}$ & $\begin{array}{l}\text { PMMA, Back Plate, } \\
\text { Mid Plate (O ring) }\end{array}$ \\
\hline Back Plate & $\mathrm{Al}$ & $\begin{array}{l}3175 \mu \mathrm{m} \\
(0.125 ")\end{array}$ & $\begin{array}{l}(11.43 \mathrm{~cm})^{2} \\
(4.5 " x 4.5 ")\end{array}$ & $\begin{array}{l}\text { Substrate, Mid } \\
\text { Plate, }\end{array}$ \\
\hline Cavity Air & Air & $\begin{array}{c}1828.8 \mu \mathrm{m} \\
\left(0.072^{\prime \prime}\right)\end{array}$ & $\begin{array}{l}\operatorname{Max} 8.6 \mathrm{~cm} \\
(3.386 ”)\end{array}$ & $\begin{array}{l}\text { Au, Mask, PMMA, } \\
\text { Mid Plate, Substrate }\end{array}$ \\
\hline Cooling Block & Water & $11.43 \mathrm{~cm}$ & $\begin{array}{l}(11.43 \mathrm{~cm})^{2} \\
(4.5 " \times 4.5 ")\end{array}$ & Back Plate \\
\hline
\end{tabular}




\section{Assembly Exposure Zone Layout}

Figure 6 is the top view of the scanned region on the assembly showing the beam window moving up and down relative to the wafer; here, a typical scan length of $8.2 \mathrm{~cm}$ is used. The seven different exposure zones can be identified from the scanned assembly area and the sample assembly layout, each of which has distinct exposure layer layout and needs a separated absorbed dose rate calculation. Zones 1-3 are fully exposed, zones 4-7 are partially exposed due to the size of beam window and scan length. The designed exposure region is the central circular region ( 2.7 inch in diameter) that further divides into open and masked regions (zone 1 and 2) depending on the absorber pattern. Exposure of zones 3 to 7 , from the front plate and below, only adds up the heat energy due to X-ray absorption. The zone 3 inner edge is the front plate inner edge, while the outer edge of zones $3,4,5,6$ are up to the mask edge, the PMMA edge, the substrate edge, and the holder's edge, respectively. Zone 7 is the four-corner region outside zone 6 .

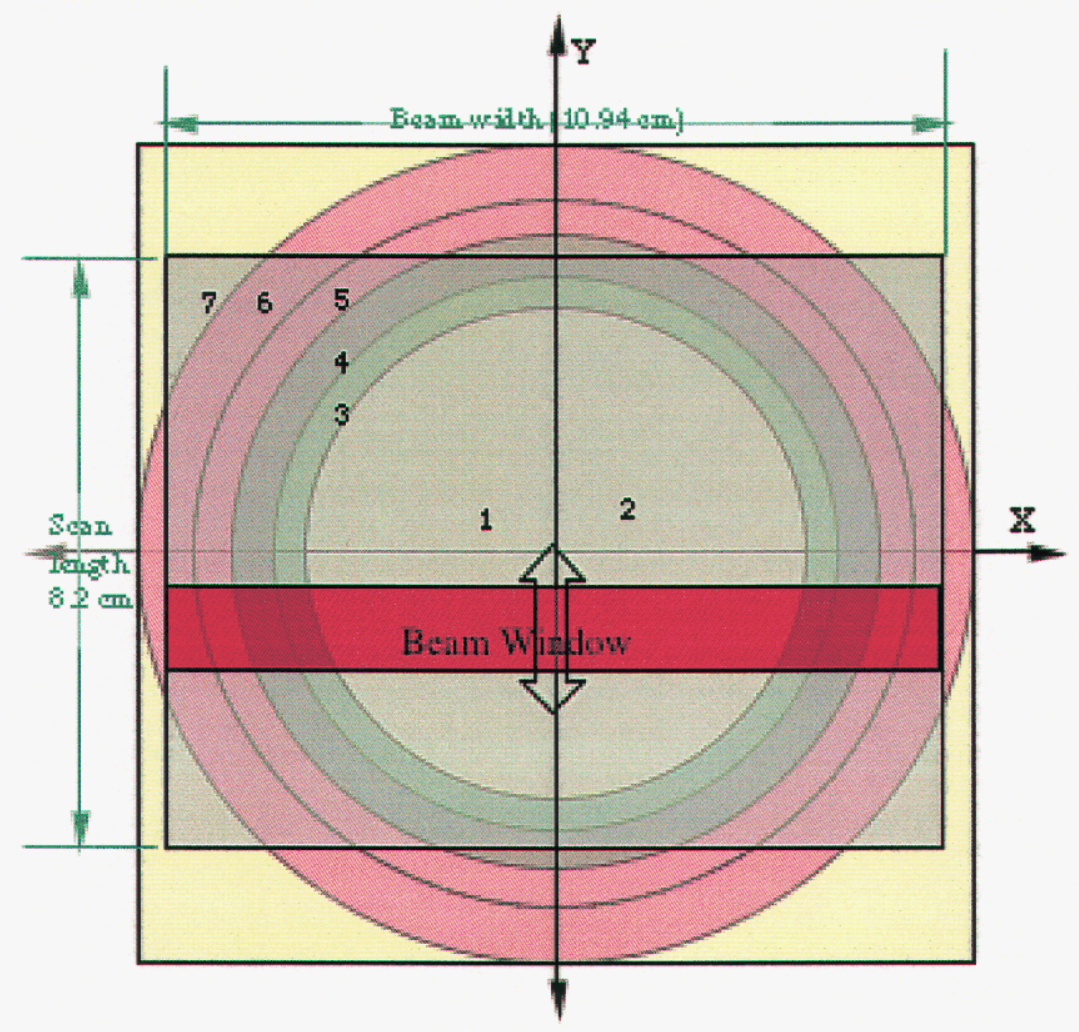

Figure 6. Top view of the assembly scanned region

Seven Exposure Zones

Main Exposure: Zone $1 \&$ 2. (open and masked by pattern) ZONE 3, Ring 3 (up to mask edge),

ZONE 4, Ring 4* (up to PMMA edge),

ZONE 5, Ring 5* (up to substrate edge),

ZONE 6, Ring $6^{*}$ (up to holder edge),

ZONE 7, outside Ring $6^{*}$,

* no complete exposure. 
The cross section view of the detailed exposure zone layout (not to scale) is shown in Figure 7. In the figure, the left boundary is the sample centerline, and the radius direction $R$ is horizontally pointing to the right. Here, the exposure path from synchrotron X-rays, filters (yellow region), and mask-wafer assembly (in blue-lined rectangular box) are shown including each path length (layer thickness or cavity distance) and horizontal exposure range (in diameters). On the left of the assembly, mask, air/absorber, cavity, resist and substrate are identified in blue labels, and the front plate, mid plate and back plate are denoted inside the layers. Note that the mid plate consists of three connected stainless steel boxes. The column nearest to the centerline is zone $1 \& 2$ that are the zones for designed LIGA exposure. All other zones exposed fully or partly are located further from the centerline.

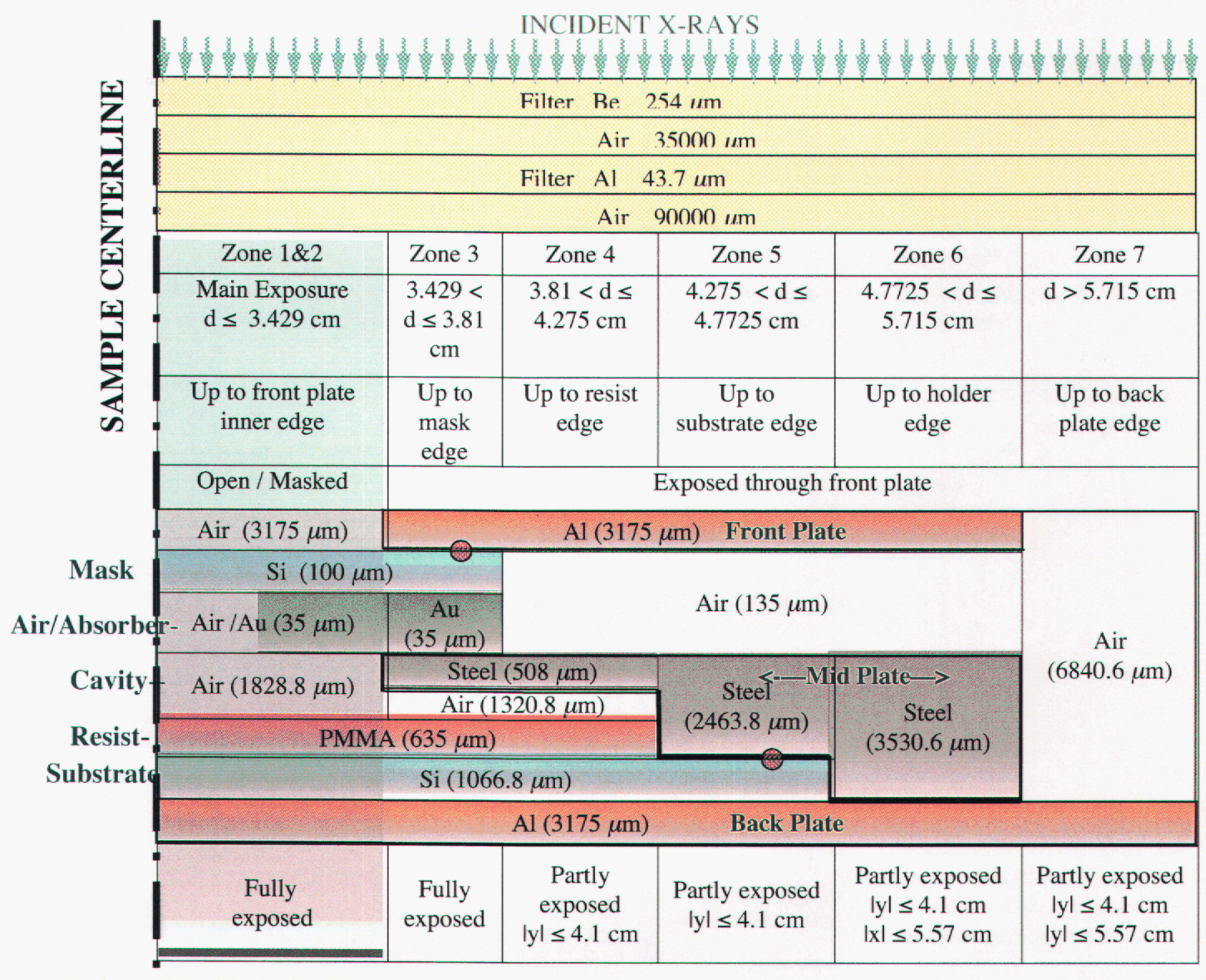

\section{$R$}

Figure 7. Cross-section view of the exposure zones (not to scale) 


\section{X-Ray Absorbed Dose Rate in the Assembly}

Sandia-developed LIGA exposure and development software LEX-D V7.54 was used to calculate X-ray absorption in materials for seven exposure zones during synchrotron X-ray exposure. These volumetric heat sources generate heat fluxes inside the assembly by thermal conduction and transferring heat outside of the assembly by thermal convection, and thermal radiation.

Table 2 lists the calculated average and top absorption dose rates $\left(\mathrm{W} / \mathrm{m}^{3}\right)$ in each material for all exposure zones including filters based on a mean current of $280.5 \mathrm{~mA}$. The data after each material is its thickness (in microns).

Table 2. Absorbed dose rate $\left[\mathrm{W} / \mathrm{m}^{3}\right]$ of materials in each zone (under each material is thickness in $\mu \mathrm{m}$ )

\begin{tabular}{|c|c|c|c|c|c|c|c|}
\hline FILTERS & $\begin{array}{c}\text { Average } \\
\text { /Peak } \\
\text { Dose rate }\end{array}$ & $\begin{array}{c}\text { ZONEI } \\
\text { (open) }\end{array}$ & $\begin{array}{c}\text { Average } \\
\text { /Peak } \\
\text { Dose rate }\end{array}$ & $\begin{array}{c}\text { ZONE2 } \\
\text { (mask) }\end{array}$ & $\begin{array}{c}\text { Average } \\
\text { /peak } \\
\text { Dose rate }\end{array}$ & ZONE3 & $\begin{array}{l}\text { Average } \\
\text { /Peak } \\
\text { Dose rate }\end{array}$ \\
\hline $\begin{array}{c}\mathrm{Be} \\
(254)\end{array}$ & $\begin{array}{l}1.540 \mathrm{e} 7 \\
2.779 \mathrm{e} 9\end{array}$ & $\begin{array}{c}\mathrm{Si} \\
(100)\end{array}$ & $\begin{array}{l}5.608 \mathrm{e} 6 \\
1.243 \mathrm{e} 7\end{array}$ & $\begin{array}{c}\mathrm{Si} \\
(100)\end{array}$ & $\begin{array}{l}5.608 \mathrm{e} 6 \\
1.243 \mathrm{e} 7\end{array}$ & $\begin{array}{c}\mathrm{Al} \\
(3175)\end{array}$ & $\begin{array}{l}2.967 \mathrm{e} 5 \\
1.028 \mathrm{e} 7\end{array}$ \\
\hline $\begin{array}{c}\text { Air } \\
(35000)\end{array}$ & $\begin{array}{l}1.501 \mathrm{e} 4 \\
1.934 \mathrm{e} 4\end{array}$ & $\begin{array}{c}\text { Air } \\
(1863.8)\end{array}$ & $\begin{array}{l}1.931 \mathrm{e} 2 \\
1.836 \mathrm{e} 2\end{array}$ & $\begin{array}{l}\mathrm{Au} \\
(35)\end{array}$ & $\begin{array}{l}1.225 \mathrm{e} 7 \\
1.167 \mathrm{e} 8\end{array}$ & $\begin{array}{c}\mathrm{Si} \\
(100)\end{array}$ & $\begin{array}{l}4.307 \mathrm{e} 3 \\
4.279 \mathrm{e} 3\end{array}$ \\
\hline $\begin{array}{c}\mathrm{Al} \\
(43.7)\end{array}$ & $\begin{array}{l}3.888 \mathrm{e} 7 \\
1.285 \mathrm{e} 8\end{array}$ & $\begin{array}{c}\text { PMMA } \\
(635)\end{array}$ & $\begin{array}{l}1.119 \mathrm{e} 5 \\
1.212 \mathrm{e} 5\end{array}$ & $\begin{array}{c}\text { Air } \\
(1828.8)\end{array}$ & $\begin{array}{l}1.471 \mathrm{e}-1 \\
1.150 \mathrm{e}-1\end{array}$ & $\begin{array}{c}\mathrm{Au} \\
(35)\end{array}$ & $\begin{array}{l}1.458 \mathrm{e} 5 \\
6.156 \mathrm{e} 5\end{array}$ \\
\hline $\begin{array}{c}\text { Air } \\
(90000)\end{array}$ & $\begin{array}{l}1.071 \mathrm{e} 3 \\
1.165 \mathrm{e} 3\end{array}$ & \multirow[t]{2}{*}{$\begin{array}{c}\mathrm{Si} \\
(1066.8)\end{array}$} & \multirow[t]{2}{*}{$\begin{array}{l}3.077 \mathrm{e} 5 \\
1.875 \mathrm{e} 6\end{array}$} & \multirow[t]{2}{*}{$\begin{array}{c}\text { PMMA } \\
(635)\end{array}$} & \multirow[t]{2}{*}{$\begin{array}{l}1.035 \mathrm{e} 2 \\
7.467 \mathrm{el}\end{array}$} & $\begin{array}{l}\text { Steel } \\
(508)\end{array}$ & $\begin{array}{l}4.811 \mathrm{e} 2 \\
2.325 \mathrm{e} 3\end{array}$ \\
\hline & & & & & & \multirow{2}{*}{$\begin{array}{c}\text { Air } \\
(1320.8)\end{array}$} & \multirow{2}{*}{$\begin{array}{l}2.183 e-4 \\
1.236 e-4\end{array}$} \\
\hline \multirow[t]{2}{*}{ ZONE4 } & \multirow{2}{*}{$\begin{array}{c}\text { Average } \\
\text { /Peak } \\
\text { Dose rate }\end{array}$} & $\mathrm{Al}(3175)$ & $8.735 \mathrm{e} 3$ & $\mathrm{Si}$ & $6.213 \mathrm{e} 2$ & & \\
\hline & & & & & & $\begin{array}{l}\text { PMMA } \\
(635)\end{array}$ & $\begin{array}{l}1.444 \mathrm{e}-1 \\
5.170 \mathrm{e}-2\end{array}$ \\
\hline $\mathrm{Al}$ & $2.967 \mathrm{e} 5$ & & & $\mathrm{Al}$ & $1.648 \mathrm{e} 2$ & & \\
\hline & $1.028 \mathrm{e} 7$ & ZONE5 & Average & & & $\begin{array}{c}\mathrm{Si} \\
(1066.8)\end{array}$ & $\begin{array}{l}1.202 \\
1.277\end{array}$ \\
\hline Air & $5.426 \mathrm{e}-1$ & & $\begin{array}{c}\text { /Peak } \\
\text { Dose rate }\end{array}$ & & & & $5.657 \mathrm{e}-1$ \\
\hline & & & & ZONE6 & Average & $(3175)$ & $7.659 \mathrm{e}-1$ \\
\hline $\begin{array}{l}\text { Steel } \\
(508)\end{array}$ & $\begin{array}{l}1.132 \mathrm{e} 4 \\
9.324 \mathrm{e} 4\end{array}$ & $\begin{array}{c}\mathrm{Al} \\
(3175)\end{array}$ & $\begin{array}{l}2.967 \mathrm{e} 5 \\
1.028 \mathrm{e} 7\end{array}$ & & $\begin{array}{c}\text { /Peak } \\
\text { Dose rate }\end{array}$ & & \\
\hline Air & $1.809 \mathrm{e}-3$ & $\begin{array}{c}\text { Air } \\
(135)\end{array}$ & $\begin{array}{l}5.426 \mathrm{e}-1 \\
4.058 \mathrm{e}-1\end{array}$ & $\begin{array}{c}\mathrm{Al} \\
(3175)\end{array}$ & $\begin{array}{l}2.967 \mathrm{e} 5 \\
1.028 \mathrm{e} 7\end{array}$ & & \\
\hline & & & & & & ZONE7 & Average \\
\hline $\begin{array}{c}\text { PMMA } \\
(635)\end{array}$ & $\begin{array}{c}1.173 \\
4.441 \mathrm{e}-1\end{array}$ & $\begin{array}{c}\text { steel } \\
(2463.8)\end{array}$ & $\begin{array}{l}2.347 \mathrm{e} 3 \\
9.324 \mathrm{e} 4\end{array}$ & $\begin{array}{c}\text { Air } \\
(135)\end{array}$ & $\begin{array}{l}5.426 \mathrm{e}-1 \\
4.058 \mathrm{e}-1\end{array}$ & & $\begin{array}{c}\text { /Peak } \\
\text { Dose rate }\end{array}$ \\
\hline $\begin{array}{c}\mathrm{Si} \\
(1066.8)\end{array}$ & $\begin{array}{l}1.006 \mathrm{e} 1 \\
1.099 \mathrm{el}\end{array}$ & $\begin{array}{c}\mathrm{Si} \\
(1066.8)\end{array}$ & $\begin{array}{l}2.210 e-5 \\
2.133 e-5\end{array}$ & $\begin{array}{c}\text { steel } \\
(3530.6)\end{array}$ & $\begin{array}{l}1.638 \mathrm{e} 3 \\
9.324 \mathrm{e} 4\end{array}$ & $\begin{array}{c}\text { Air } \\
(6840.6)\end{array}$ & $\begin{array}{l}1.064 \mathrm{e}-3 \\
1.165 \mathrm{e}-3\end{array}$ \\
\hline$\underset{(3175)}{\mathrm{Al}}$ & $\begin{array}{l}6.334 \\
2.135\end{array}$ & $\begin{array}{c}\mathrm{Al} \\
(3175)\end{array}$ & $\begin{array}{l}3.844 \mathrm{e}-6 \\
1.211 \mathrm{e}-5\end{array}$ & $\begin{array}{c}\mathrm{Al} \\
(3175)\end{array}$ & $\begin{array}{l}9.412 \mathrm{e}-7 \\
3.151 \mathrm{e}-7\end{array}$ & $\begin{array}{c}\mathrm{Al} \\
(3175)\end{array}$ & $\begin{array}{l}3.081 \mathrm{e} 5 \\
1.107 \mathrm{e} 7\end{array}$ \\
\hline
\end{tabular}


Intentionally Left Blank 


\section{Thermal Analysis of the LIGA Resist Exposure}

Once the heat sources resulting from the X-ray absorption are known, temperatures in the assembly due to these heat sources and the heat transfer in the assembly can be determined. Assembly heat transfer includes various mechanisms: thermal conduction transports and redistributes heat energy generated inside the assembly through all interfaces and the air inside the cavity; forced convection due to the cooling nitrogen jets carries heat energy away from the mask surface; forced convection due to the hutch ceiling fan moves the air over assembly surfaces; natural convection due to buoyancy at the front plate surface may not be ignored since the wafer scanner scans vertically; thermal radiation in the inner cavity exchanges heat among participating surfaces; thermal radiation radiates heat to the surroundings on all outer surfaces of the assembly.

Figure 8 is the cross section of the assembly including the water block attached on the back of the back plate. We would expect that temperature rise of the mask would be caused by absorption of X-rays, both directly incident on the mask and transmitted through the mask holder. The temperature rise on the resist PMMA can result from transmitted X-rays, heat fluxes conducted from cavity air, silicon substrate, and radiated from cavity surfaces including the bottom surfaces of absorber (masked region) and mask (open region), and the inner and partial bottom surface of mid-plate. Detailed calculations must be performed to quantitatively determine the contribution of each mechanism to the overall heat flow in the composite assembly.

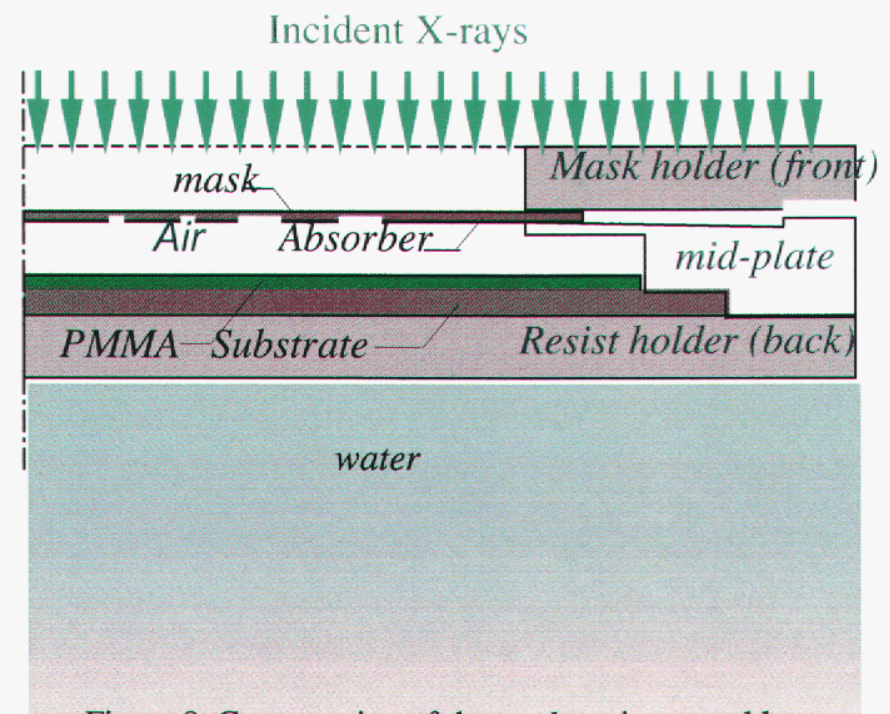

Figure 8. Cross section of the mask-resist assembly

Table 3 presents the material thermophysical properties of seven materials used. As shown in Table 3, the PMMA thermal diffusivity is almost three orders of magnitudes smaller than that of silicon. This means that the time required for the PMMA temperature to settle (i.e., thermal relaxation time) is very much longer than for silicon. Also, the specific heat data indicate that 
the energy required to increase the PMMA temperature a given amount is twice that required for silicon.

Table 3. Thermo-physical properties of materials

\begin{tabular}{cccccc}
\hline & $\begin{array}{c}\text { Density } \\
{\left[\mathrm{kg} / \mathrm{m}^{3}\right]}\end{array}$ & $\begin{array}{c}\text { Conductivity } \\
{[\mathrm{W} / \mathrm{m} \mathrm{K}]}\end{array}$ & $\begin{array}{c}\text { Specific } \\
\text { Heat } \\
{[\mathrm{J} / \mathrm{kg} \mathrm{K}]}\end{array}$ & $\begin{array}{c}\text { Thermal } \\
\text { Diffusvity } \\
{\left[\mathrm{m}^{2} / \mathrm{s}\right]}\end{array}$ & Emissivity \\
\hline Air & 1.293 & 0.0263 & 1007. & $2.020 \mathrm{e}-5$ & \\
$\mathrm{Al}$ & 2702. & 237. & 903. & $9.714 \mathrm{e}-5$ & 0.095 \\
$\mathrm{Si}$ & 2330. & 148. & 712. & $8.921 \mathrm{e}-5$ & 0.5 \\
$\mathrm{Au}$ & 19300. & 317. & 129. & $1.273 \mathrm{e}-4$ & 0.04 \\
Steel & 7800. & 48. & 452. & $1.362 \mathrm{e}-5$ & 0.2 \\
PMMA & 1190. & 0.25 & 1500. & $1.401 \mathrm{e}-7$ & 0.8 \\
Water & 1000. & 0.606 & 4181. & $1.45 \mathrm{e}-7$ & 0.96 \\
\hline
\end{tabular}

\section{Heat Source Calculation}

X-ray absorbed dose rate in the assembly, computed using LEX-D v7.54, is converted to volumetric heat sources in materials by a user subroutine implemented in commercial software ABAQUS. Only the region of the material located within the instantaneous scanning window absorbs X-ray energy, so the average absorbed dose rate in each exposed material layer is calculated as

$$
\begin{array}{ll}
y_{0}=-(1 / 2) S_{l} \cos (\omega t), & \\
Q(x, y, z)=d D / d t(\mathrm{x}, y, z) *\left(S_{l} / W_{h}\right) * F(t), & \text { If }\left|y-y_{0}\right| \leq 0.5 W_{h} \text { and }|x| \leq 0.5 W_{w} \\
Q(x, y, z)=0 . & \text { If }\left|y-y_{0}\right|>0.5 W_{h} \text { or }|x|>0.5 W_{w}
\end{array}
$$

Here, the $\mathrm{x}-\mathrm{y}$ plane is perpendicular to the exposure direction $z, \mathrm{y}$ is the wafer scanning direction, and $y_{0}$ is instantaneous central scanning position. $Q(\mathrm{x}, y, z)$ is the average volumetric heat source at material point $(\mathrm{x}, y, z)$ over the beam window height. Calculated from LEX-D, $d D / d t(\mathrm{x}, y, z)$ is the average absorbed dose-rate over the whole scan-length at the material point $(\mathrm{x}, y, z)$ that depends on the exposure zone and the depth in the zone. $S_{l}, W_{h}$ and $W_{w}$ are scan-length, beam window height and width, respectively. $\omega$ is scan frequency, and $F(t)$ is a dimensionless beam current factor changed with exposure time $t$.

\section{Boundary and Initial Conditions}

Heat transfer calculations were performed for the assembly (all nine components including cavity air and water block) by using ABAQUS v6.3. Four different boundary conditions are applied for this transient heat transfer problem: 1) heat radiates to the ambient from all outer surfaces, 2) natural convection along the top surface of mask holder, 3) forced convective heat transfer on the top surface of silicon mask resulted from two nitrogen cooling arrays, which 
will be elaborated in the next section, 4) optional fixed temperature boundary condition as ambient temperature $\left(25^{\circ} \mathrm{C}\right)$ at outer surfaces of the water-cooling block because observed water temperature can grow higher than room temperature during exposure. Initial temperature of all elements is the same as the ambient temperature.

The assembly was meshed into a mid-sized mesh with 3122 nodes, 1932 finite elements and 779 contact surface elements. The computing time for 5000 seconds of real time heat transfer is about two days on a SunBlade 1000 workstation.

\section{Forced and Natural Convective Heat Transfer}

Forced convection heat transfer due to nitrogen jets and natural convection heat transfer due to buoyancy are all included as surface boundary conditions in heat transfer calculation of the assembly. The nitrogen jets create stagnation flows at the upper mask surface inside the exposure window (Figure 4). To estimate the forced convective heat transfer at the mask upper surface due to nitrogen jets, a dimensionless forced convective heat transfer equation in a turbulent thermal boundary layer on flat plate is employed since the Reynolds number is large [5],

$$
N u=0.036 \operatorname{Re}^{0.8} \operatorname{Pr}^{1 / 3}
$$

where $N u=h L / k$ is Nusselt number, a dimensionless temperature gradient at the surface, providing a measure of the convection heat transfer at the surface, and $\operatorname{Pr}=v / \alpha$ is Prandtl number, a ratio of the momentum and thermal diffusivities. Here, $u=2 \mathrm{~m} / \mathrm{s}$, the nitrogen jet exit velocity measured with an anemometer; $L=0.1094 \mathrm{~m}$; and $v=15.86 \times 10^{-6} \mathrm{~m}^{2} / \mathrm{s}, \alpha=$ $22.1 \times 10^{-6} \mathrm{~m}^{2} / \mathrm{s}, k=0.0259 \mathrm{~W} / \mathrm{m}-\mathrm{K}$, all for nitrogen at $25^{\circ} \mathrm{C}$. Now $R e_{L}=u L / v=13796, P r=$ 0.718 , so $N u=66.09, h=15.65 \mathrm{~W} / \mathrm{m}^{2} \mathrm{~K}$. The flow of gas near the sample surface is dominated by the flow of nitrogen from the tubes; the airflow caused by the hutch fan at the hutch ceiling seems negligible. Therefore, we consider only forced convection by the nitrogen flow.

The influence of natural convective heat transfer at the front plate surface due to buoyancy should be estimated. Since the Rayleigh number is in the laminar flow range, Churchill and Chu's natural convection at vertical plate [5] is employed.

$$
\begin{array}{ll}
N u_{L}=\frac{h L}{k}=0.68+\frac{0.670 R a_{L}{ }^{1 / 4}}{\left(1+\left(0.492 / P_{r}\right)^{9 / 16}\right)^{4 / 9}} & \text { if } R a_{L}<10^{9} \\
R a_{L}=\frac{g \beta\left(T_{s}-T_{\infty}\right) L^{3}}{v \alpha} & \beta=-\frac{1}{\rho}\left(\frac{\partial \rho}{\partial T_{f}}\right)_{p}=\frac{1}{\rho} \frac{p}{R T_{f}{ }^{2}}=\frac{1}{T_{f}}
\end{array}
$$

The Rayleigh number is a measure of relative magnitude of the buoyancy and viscous forces in the flow, and $\beta$ is the volumetric thermal expansion coefficient. The film temperature $T_{f}$ is $0.5\left(T_{\infty}+T_{s}\right)$, with $T_{\infty}=298.63 \mathrm{~K}$, For an estimated surface temperature $T_{s}=323.15 \mathrm{~K}=50{ }^{\circ} \mathrm{C}$, 
$R a_{L}=2,884,283<10^{9}$, is in laminar-flow range. For air, $v=17 \times 10^{-6} \mathrm{~m}^{2} / \mathrm{s}, \alpha=24 \times 10^{-6} \mathrm{~m}^{2} / \mathrm{s}$, $P_{r}=0.708, k=0.0263 \mathrm{~W} / \mathrm{m} \mathrm{K}$, all evaluated at $T_{f}$, so $\mathrm{Nu}_{\mathrm{L}}=21.87, h=5.03 \mathrm{~W} / \mathrm{m}^{2} \mathrm{~K}$, a much smaller value than in forced convection. Here $L=4.5$ ' $=0.1143 \mathrm{~m}$. Note that the jet interference is not considered here. 


\section{Results of Absorption Dose and Time Integration Heat Fluxes}

The assembly temperature calculations for a 5000-second real time exposure at ALS 3.3.2 beam line with beam current decreasing from initial $262 \mathrm{~mA}$ to final $236 \mathrm{~mA}$ are summarized in the following:

\section{Energy Absorption in the Mask-Resist Assembly Components}

Figure 9 gives the average surface absorption of each component (volumetric absorption multiplying thickness). The front plate, mask plate, mask absorber, and the silicon substrate (open region) have the highest absorption, followed by PMMA and the back plate (open region), and by mid-plate and all materials in masked regions. The mid-plate has relatively lower absorption, but it becomes a major pathway for heat flow, as will be shown later.

The average surface absorption on the open area of PMMA is about eight times smaller than that for the mask plate (50 times smaller in volumetric absorption), and PMMA has twice as large specific heat, so its temperature is not likely to rise greatly by absorption alone. The absorption on the masked area of PMMA is more than three orders of magnitude smaller than that of PMMA open area.

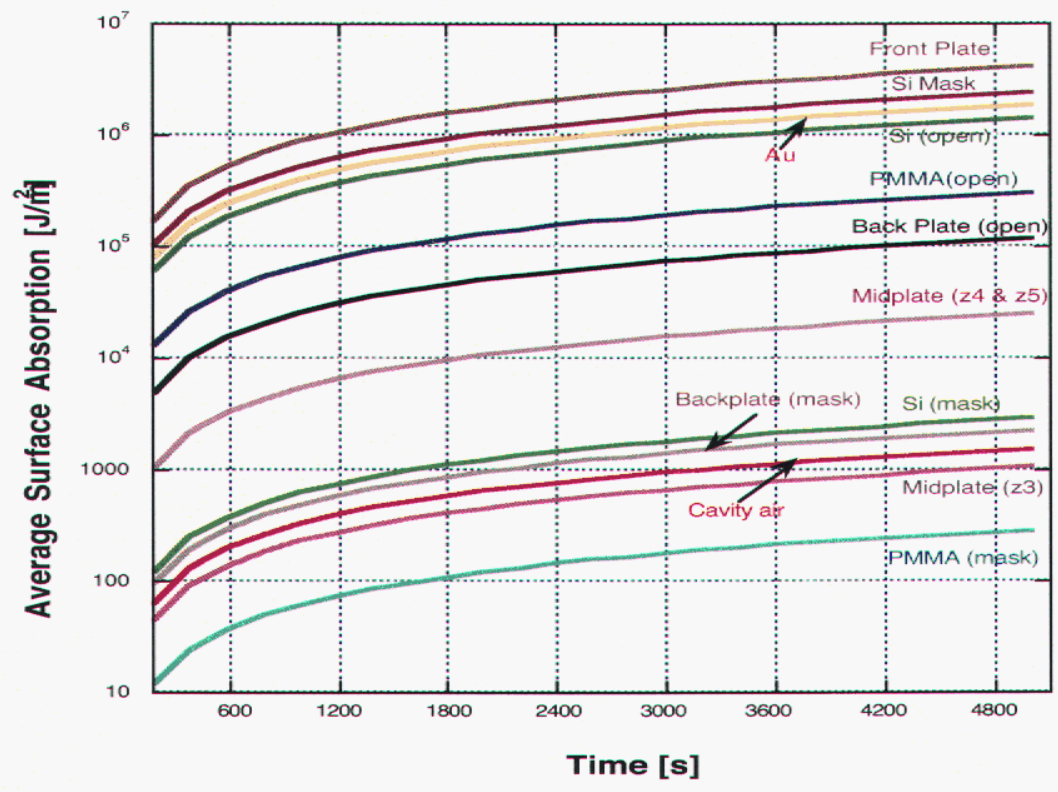

Figure 9. Average surface X-ray absorptions

\section{Heat Conduction at Interfaces}

Figure 10 gives cumulative time integrated heat conductive fluxes across interfaces. Here, good contact (no temperature jump) is assumed at each interface. We can see that the six highest curves are close to each other. They are fluxes between absorber and mid-plate, mask 
plate and absorber, back plate and water, mask plate and front plate, substrate and back plate, mid-plate and substrate. Followed are flux between PMMA and substrate, an order of magnitude lower, and the flux between mid-plate and back plate, two orders of magnitude lower.

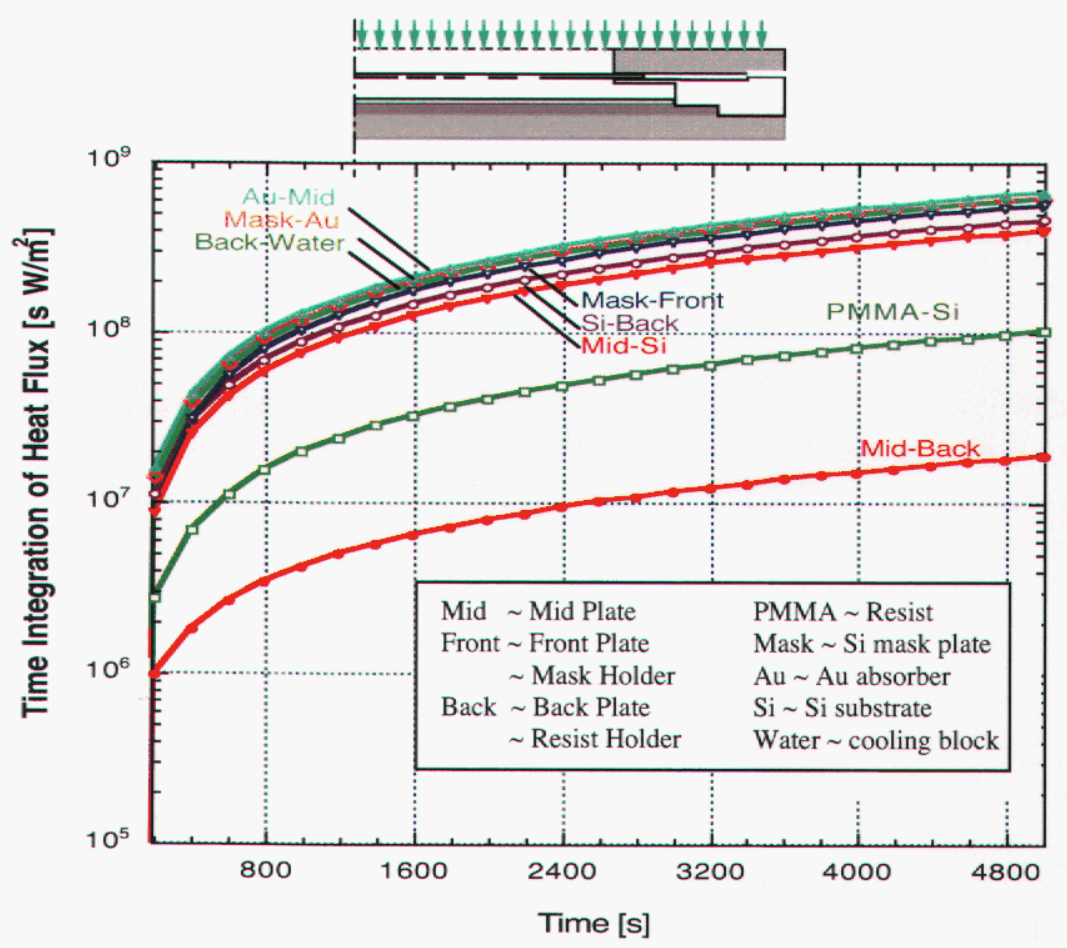

Figure 10. Cumulative time integrated interfacial heat fluxes

The computed results indicate that the main heat conduction path begins at mask plate and mask holder, then going sequentially through gold mask absorber, mid-plate, substrate, back plate and water. In addition, the substrate gives a small part of heat energy upward to PMMA, while most of the heat energy coming to substrate goes to back plate. However, this energy flow to PMMA from the substrate is important, because it is an order of magnitude larger than the PMMA X-ray absorbed energy. Besides, the mid-plate also losses little heat energy to the back plate. Therefore, if water cooling functions very well, then most of the heat energy coming to substrate and mid plate will be directed to back plate and then to water, so less heat energy will be conducted to the resist.

\section{Forced and Natural Convection Fluxes}

Figure 11 shows the cumulative time integrated forced convective flux on mask plate surface due to nitrogen jets and natural convective flux on the mask holder surface. These convective fluxes carry the heat energy away from the corresponding surfaces. Also plotted are the X-ray average surface absorption on the mask plate and the front plate for comparison.

It can be seen that nitrogen jets carry away a significant portion (about $40 \%$ ) of silicon mask average surface absorption, while the effect of the natural convection is negligible compared with front plate absorption (less than $1 \%$ ). Thus, nitrogen-jet cooling is very efficient. Note 
that the min and max forced convective flux ranges is due to the oscillating mask temperature resulting from scanning.

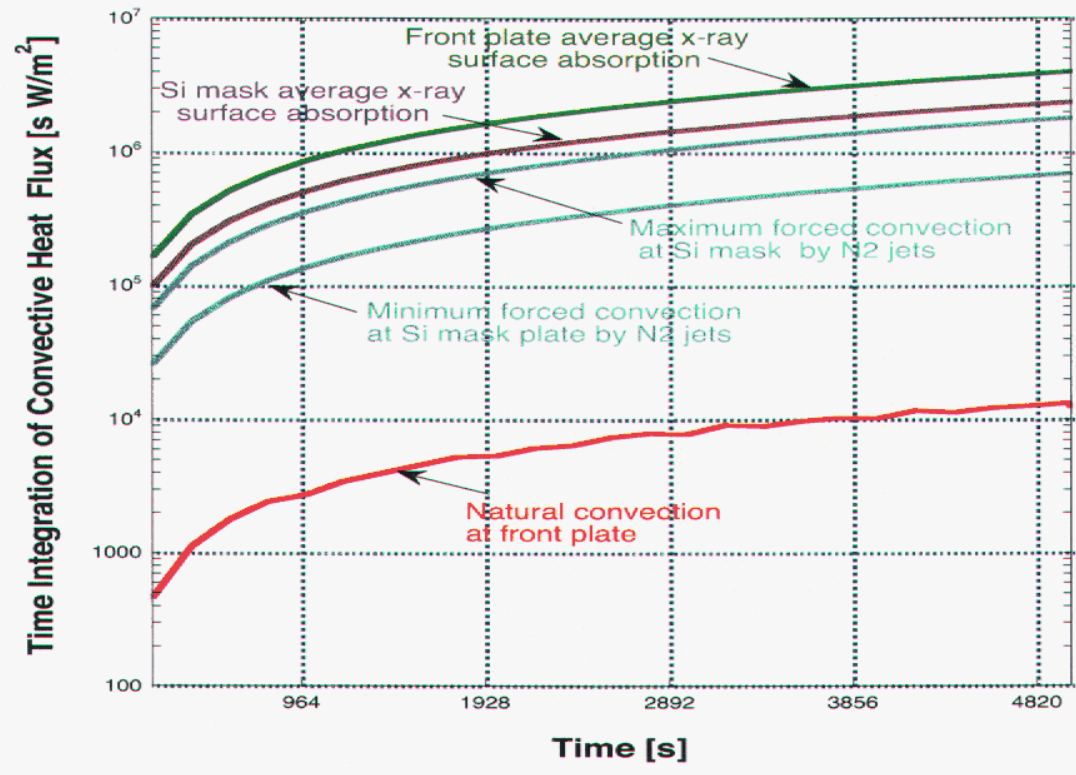

Figure 11. Cumulative convective heat fluxes at sample top surfaces.

\section{Thermal Radiation in Inner Cavity}

Figure 12 shows cumulative time integrated, net thermal radiation fluxes at each surface of inner cavity by choosing maximum radiated flux on a surface element at each surface.

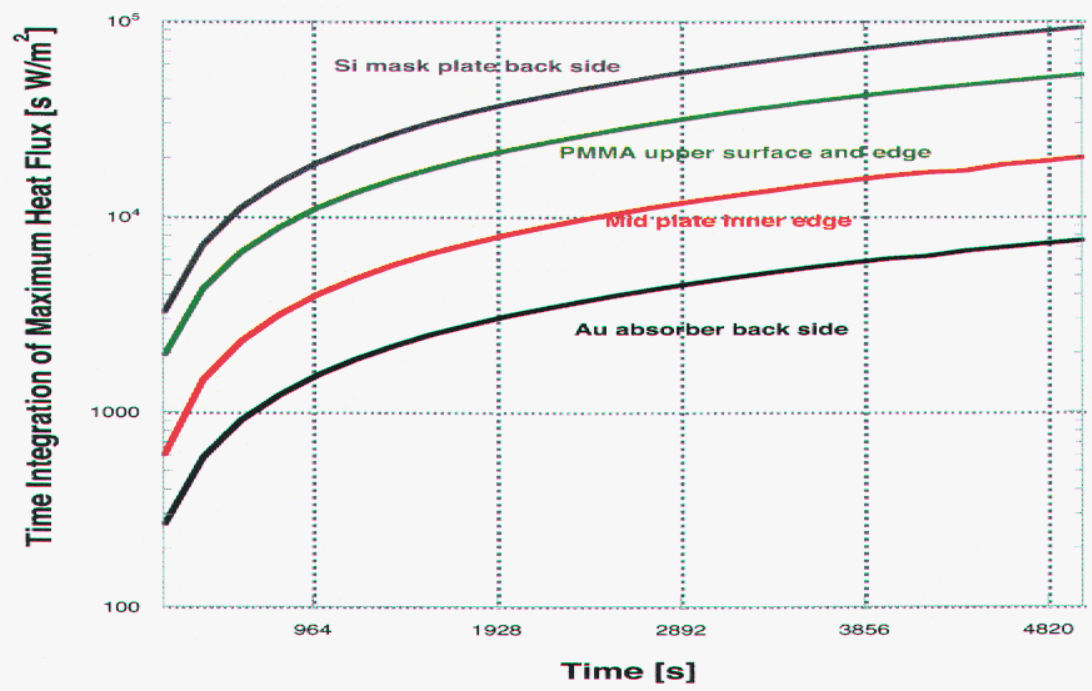

Figure 12. Cumulative time integrated, net thermal radiation fluxes at cavity surfaces

PMMA surface receives radiated heat fluxes from the bottom surfaces of mask plate and absorber, and from inner side and partial bottom surfaces of mid-plate because of its lower 
temperature. The radiation to the small substrate ring is ignored here. It can be seen from the curve values that radiated heat flux received by PMMA is three orders of magnitudes lower than the heat flux conducted from the substrate (Figure10), and one order of magnitude smaller than the average X-ray surface absorption (Figure 9). Therefore, it is not the major concern of PMMA temperature rise.

\section{Sources That Raise PMMA Temperature}

In contrast to the mask plate temperature rise due to direct X-ray absorption, the PMMA temperature rise results from many sources. Figure 13 gives the various heat fluxes coming to the PMMA. The heat flux conducted upward from substrate is the highest among all sources. Heat flux conducted from the air inside the cavity is the second, followed by X-ray absorption in the open region, and heat radiated from the cavity. X-ray absorption in the masked area is several orders of magnitude lower. Although air has a small thermal conductivity, it has a large thermal diffusivity (see Table 2), and the thickness of this air layer is only $0.18 \mathrm{~cm}$, so heat conduction from the heated mask and mask holder through the air layer to the PMMA is efficient. Note that the maximum and minimum range of heat conduction from the air layer is due to oscillating absorber and mask plate temperatures.

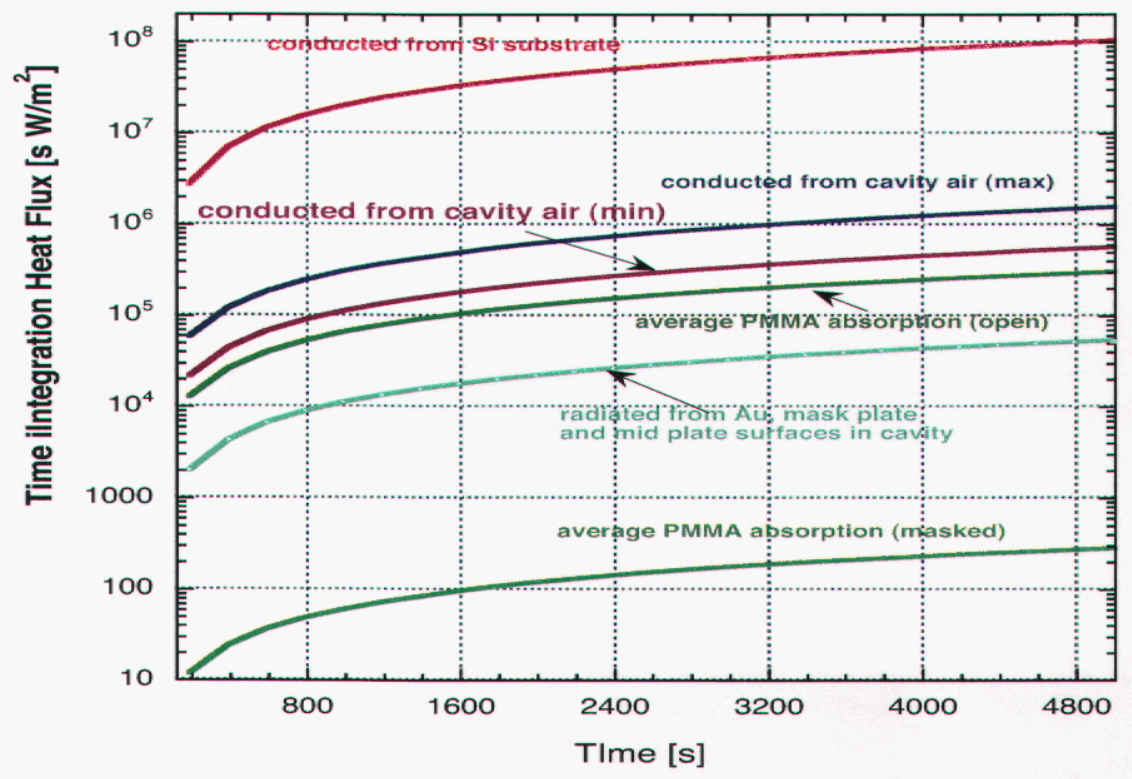

Figure 13. Absorption and cumulative heat fluxes to PMMA

Based on the data shown in Figures 9-13, the computed results can be summarized as follows: 1) nitrogen jets carry away a significant portion of the absorbed heat energy from the mask; 2) the temperature rise of the resist is not mainly due to X-ray absorption as in the common thought, but is due to heat conduction from other components in the assembly; 3 ) a better water-cooling substrate 'will absorb more heat along the main heat conductive path, reducing the heat flux conducted from substrate and cavity air to the resist. 


\section{Results of Maximum Temperature Examples}

For temperature rise on each component of the assembly, we calculated several cases to compare with the available data. We are only interested in the time history of the maximum temperature at each component, instead of instantaneous temperature profiles.

Case 1. Nitrogen jets were on. The assembly was exposed at ALS 3.3.2 beam line for 5000s with beam current changing from initial $262 \mathrm{~mA}$ to final $236 \mathrm{~mA}$ (with/without water temperature boundary conditions).

The boundary conditions include 1) forced convection by nitrogen jets (neglecting the influence of hutch ceiling fan), 2) thermal radiation from outer surface to ambient, 3) natural convection at assembly top surface, 4) fixed water-cooling block outer surface temperature as ambient temperature $\left(25^{\circ} \mathrm{C}\right)$. Here, the initial water temperature is at room temperature, not at the originally designed temperature of $20^{\circ} \mathrm{C}$. Figure 14 gives the maximum temperatures on each component. It can be seen that after initial temperature ramp-up quickly in the first few minutes, each maximum temperature reaches a temperature plateau, resulting from the effects of nitrogen jets, water block outer surface constant temperature, and beam current decreasing, in spite of some oscillations due to scanning. The temperature oscillation is gradually smoothed out by thermal diffusion along the exposure path. The maximum temperature of silicon mask and PMMA reach around $52^{\circ} \mathrm{C}$ and $26.5^{\circ} \mathrm{C}$, respectively. Temperatures of the substrate and the back plate reach $25.5^{\circ} \mathrm{C}$, and the front and mid plate reach $34.5^{\circ} \mathrm{C}$. Mask and absorber temperature results were acquired at every 20 seconds, while all others at every 200 seconds because of smaller amplitudes, but the plot still filtered out many temperature oscillations including those of the mask that were not written to file due to the limited problem size.

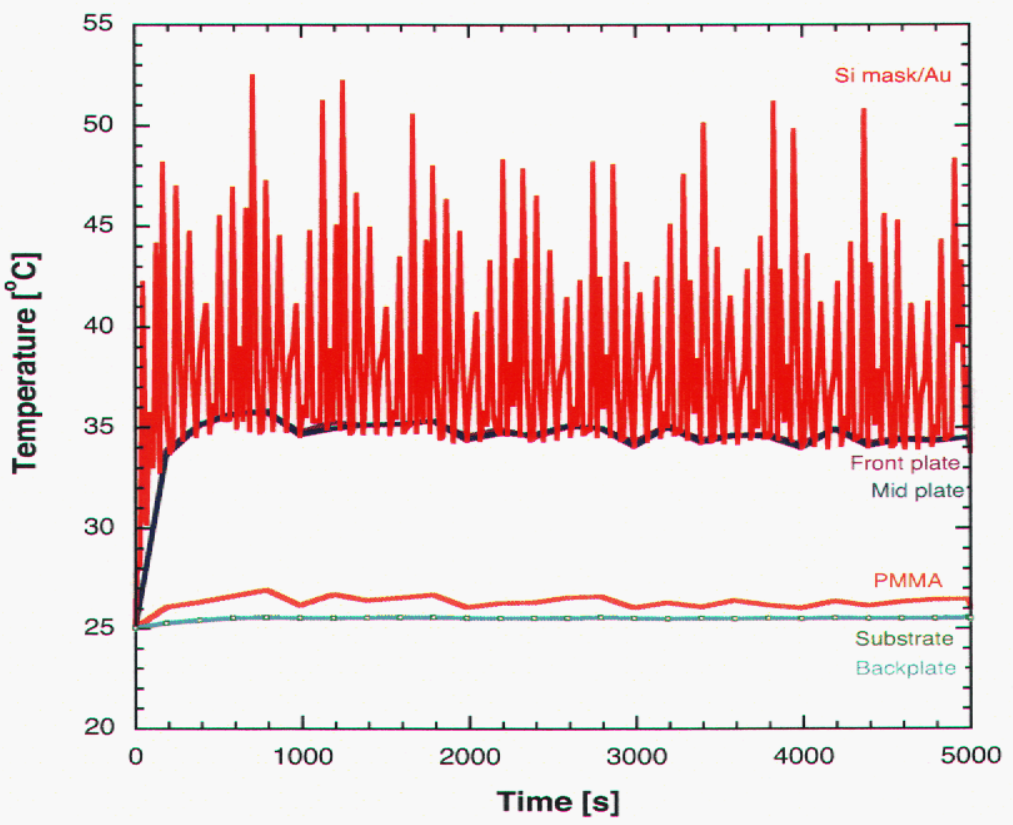

Figure 14. Time history of maximum temperature (case 1) 
Figure 15 gives the curves resulting from the same calculation as in Figure 14 except for without the fixed water temperature condition on its outer surface. Now, each maximum temperature continues to rise linearly even with nitrogen jets cooling and beam current reducing because of the rising water temperature (cooling block did not work properly). Due to the small thermal diffusivity and the large length scale (4.5"), the thermal diffusion time scale of the water block is very large (no enough time for water to carry away all the heat) such that its outer surface temperature is higher than ambient temperature. It indicates the importance of water-cooling for reducing temperature rise in the assembly.

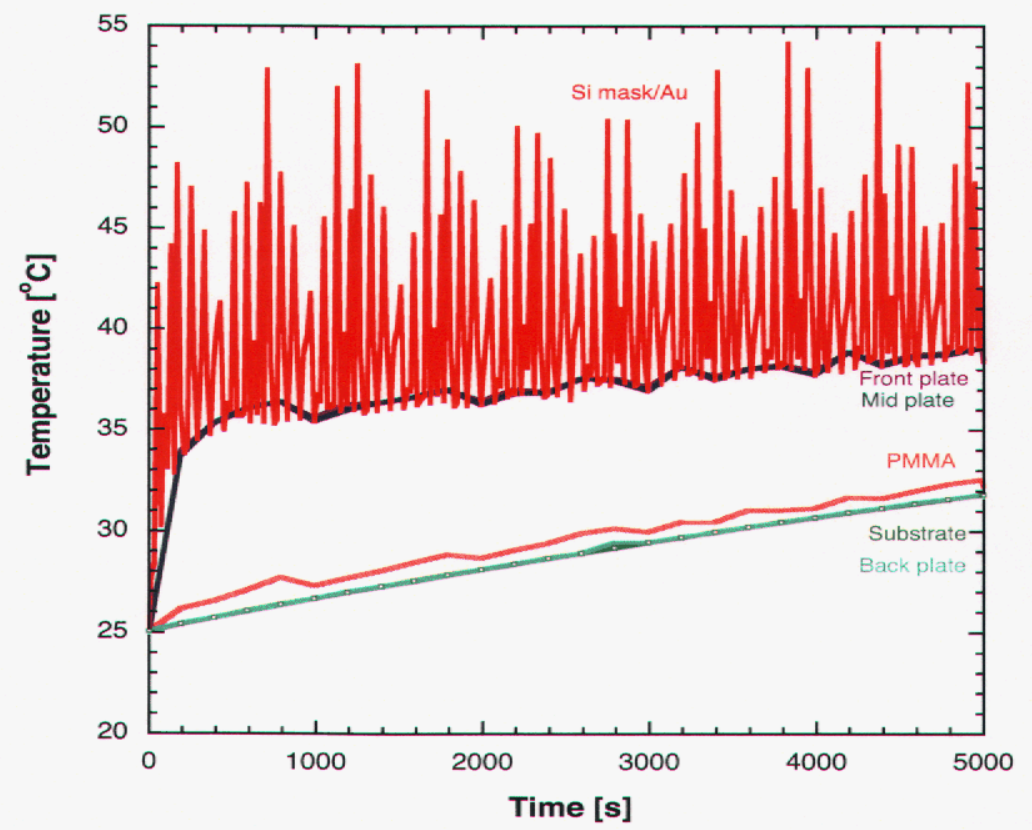

Figure 15. Time history of maximum temperature (worse case in case 1)

Results show that after 5000 seconds, temperature rises $3{ }^{\circ} \mathrm{C}$ higher for mask, $6{ }^{\circ} \mathrm{C}$ higher for resist, substrate and back plate, and $4.5^{\circ} \mathrm{C}$ higher for front and mid plate, compared with Figure 14; the water maximum temperature reaches over $30^{\circ} \mathrm{C}$. Note that the results in both Figures 14 and 15 show how well the PMMA temperature tracks the water cube temperature. If the water cooling block (and back plate) were running at the desired temperature of $\sim 20 \mathrm{C}$, we can imagine that all the curves in both figures might shift downwards $\sim 5 \mathrm{C}$.

Experimental data acquired by the Sandia LIGA group (refer to next section) lies in between the above two results, in which the water temperature increases to $27^{\circ} \mathrm{C}$, indicating the current water cooling block was not working properly at the time the experimental data were taken.

Case 2. Nitrogen jets were off. The assembly was exposed at ALS 3.3.2 beam line for 2880s with beam current changing from initial $229 \mathrm{~mA}$ to final $216 \mathrm{~mA}$, about $13 \%$ lower than in case 1. Fixed temperature water boundary condition was not applied.

Figure 16 gives the maximum temperature on each component for case 2. It can be seen that the temperature of each component is rising including water temperature (to about $29^{\circ} \mathrm{C}$ ). After 2880 seconds, the temperature rise is not very large compared to Figure 15 because of 
the lower beam current density even though the nitrogen jets were off. PMMA temperature rise is less than $5.1{ }^{\circ} \mathrm{C}$. The mask and absorber reach $53^{\circ} \mathrm{C}$, the front and mid plate reach $38.08{ }^{\circ} \mathrm{C}$, and the substrate and back plate reach $29.15^{\circ} \mathrm{C}$.

It is also interesting to note one influence of the nitrogen jets on-versus-off on the results in Figures 15 and 16. In Figure 15, with the jets on, but bad water-cooling, the average rate of temperature increase of the mask holder (front plate) and mid-plate is less than the rate of temperature increase of the back plate. This suggests that the jets are helping to cool the front of the assembly. In Figure 16, this jet cooling is absent and the front, mid and the back plates all have about the same rate of temperature increase.

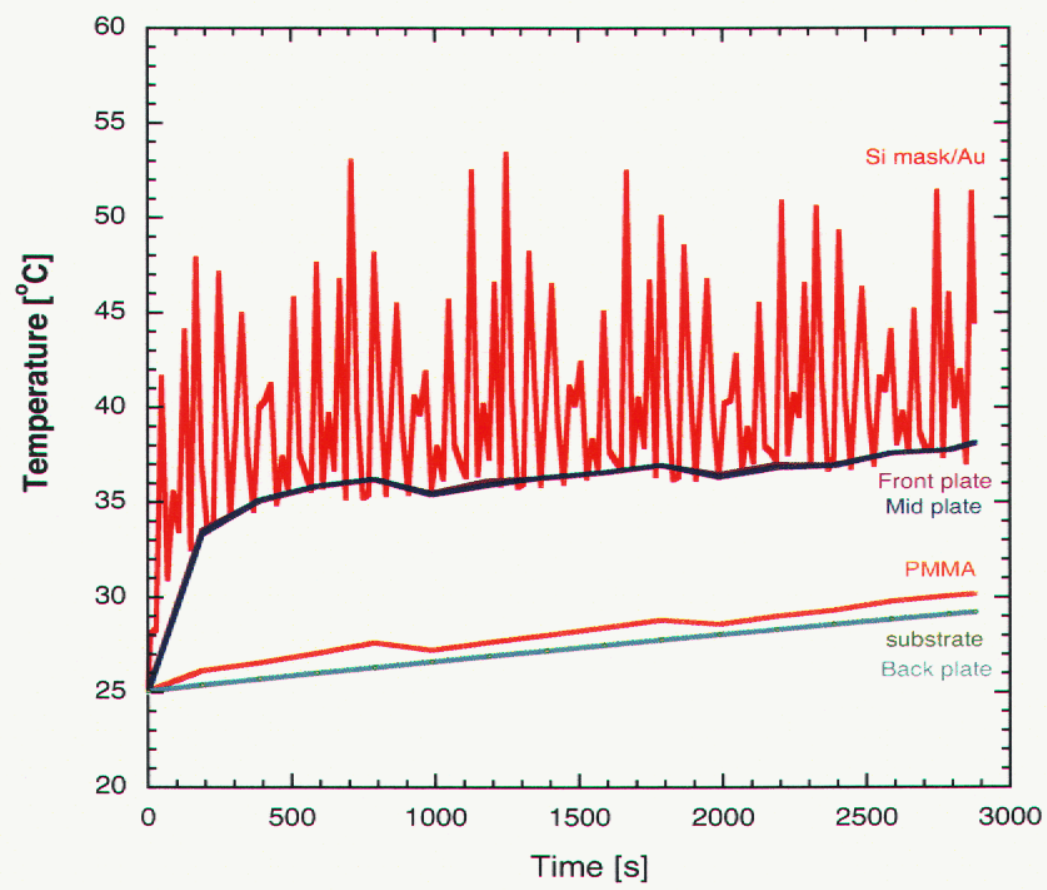

Figure 16. Time history of maximum temperature (case 2)

As shown in Figures 14-16, the maximum temperature of PMMA is higher than the silicon substrate. However, PMMA temperature is highly non-uniform due to its very low thermal conductivity and diffusivity. Temperature of PMMA top surface is higher than its bottom surface so that heat flux is able to flow from substrate upward to PMMA. The temperature of mid-plate is also non-uniform due to stainless steel's much lower thermal conductivity and diffusivity than that of the aluminum front and back plate. Temperature on the inner edge of the mid plate is much higher than its outer edge due to direct contact with absorber. Therefore, the mid plate transfers almost all its heat flux to substrate leaving only a little portion to the back plate, as shown in Figure 10. 
Intentionally Left Blank 


\section{Comparison with Temperature Measurements}

Temperature measurements of the mask-wafer assembly have been made at ALS 3.3.2 beam line on June 10, 2003 [3]. Figure 17 shows the four-thermocouple locations used (\#7 on the mask, \#3 on the front plate, \#2 on the back plate, \#1 on the water cooling block). Two different thermo-couple arrangements were used (listed in the following text box). \#2, \#3 and $\# 7$ are shield from the direct X-ray beam by copper shielding to minimize TC heating by the direct X-ray beam, so that the temperatures of the components onto which they are connected temperatures would be measured better. However, due to the shielding, the very high oscillating mask plate peak temperatures were filtered out by copper with its high thermal conductivity, so only the lower end temperatures were recorded.

Figure 18 (a)-(c) gives the measured temperature curves of these 4 locations for the computation cases 1 and 2. Case-1 measurement was conducted before 1:30 PM, while case-2 measurement was conducted after 1:30 PM. Since the data points were taken every second, the curves in Figure 18 (a) are too dense to resolve details. Thus, Figure 18 (b) and (c) show a little detail on an expanded time axis of case 1 and case 2 . We can see the intense oscillating temperature due to the wafer scanning. In Figure 18, the decreasing beam current density is also plotted against the right vertical axis, and thus, the case- 2 experiment was under a lower beam current, which is proportional to the exposure power intensity.

The amplitude of oscillating temperature decreases from top to bottom of the assembly, as expected. The time period is the scan period of $11.40^{+} \mathrm{s}$, and can be clearly identified in Figure 18 (b) and (c). Note that T2, T3 and T7 are lower than the predicted maximum temperature curves of the back plate, front plate (mask holder) and the mask plate due to shielding, while $T 1$ is close to predicted maximum temperature curve of the water cooling block. The water temperature in both cases rises higher than the ambient temperature, indicating the water-cooling was not working properly.

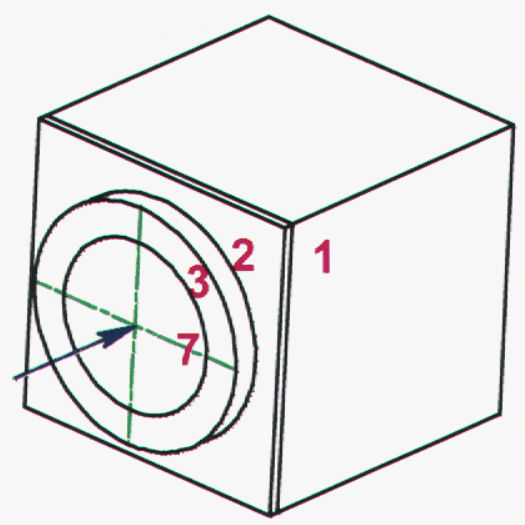

2, 3, 7: thermocouples with $0.010 " \mathrm{Cu}$ shielding. No contact. 1: thermocouples without shielding.

Figure 17. Thermocouple locations on the assembly

It can be seen that the calculated maximum temperatures are comparable with measured data for case 2, and the measured data for case 1 lie in between the two calculations for case 1 . Therefore, the estimated PMMA temperature lies between 26.5 to $30.50{ }^{\circ} \mathrm{C}$ in case 1 and 
around $30^{\circ} \mathrm{C}$ in case 2 since it cannot be measured. Both measurements and calculations suggest the water-cooling should be improved to lower the mask and the resist temperatures.

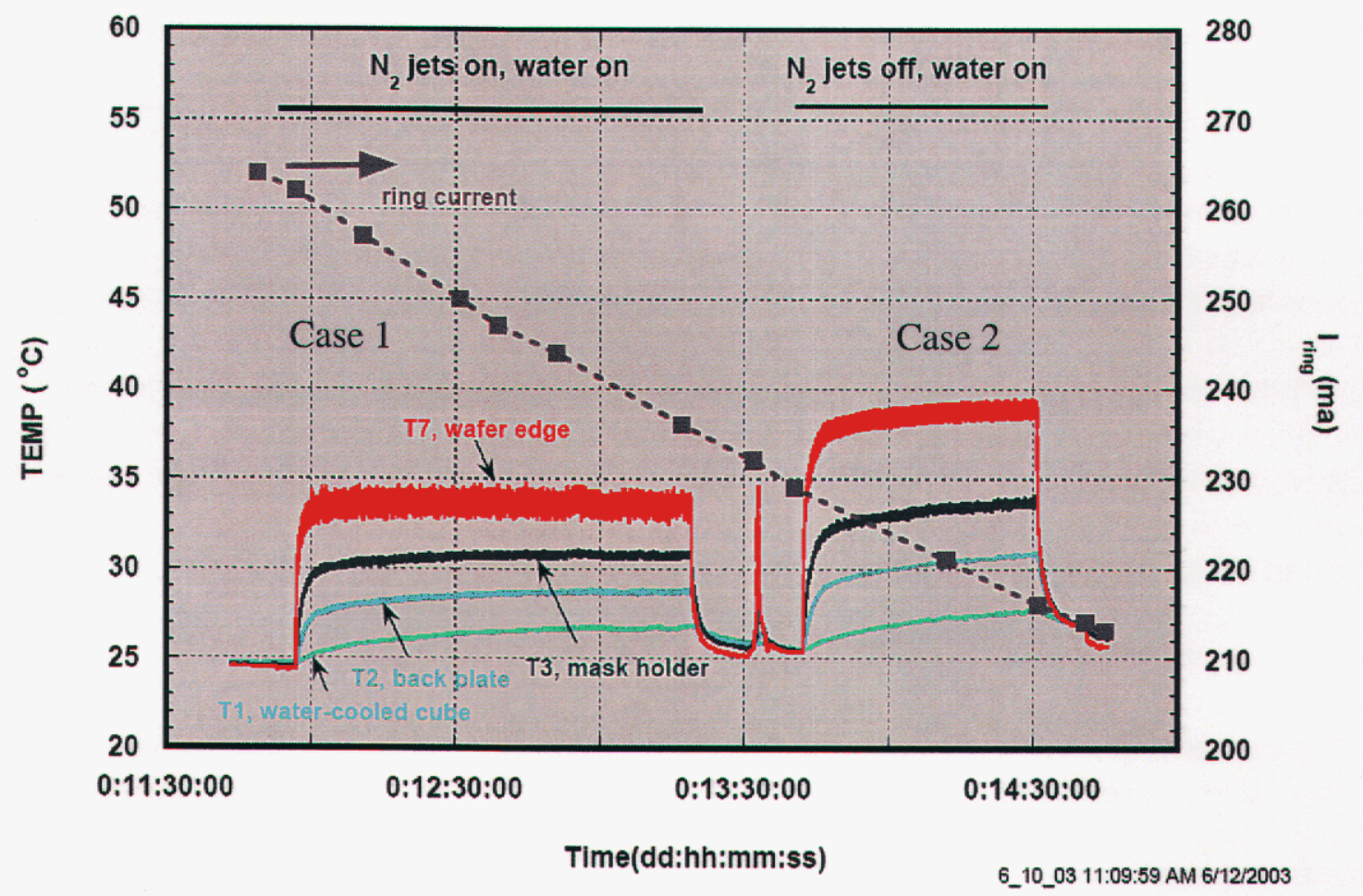

Figure 18(a). Assembly temperature measurements

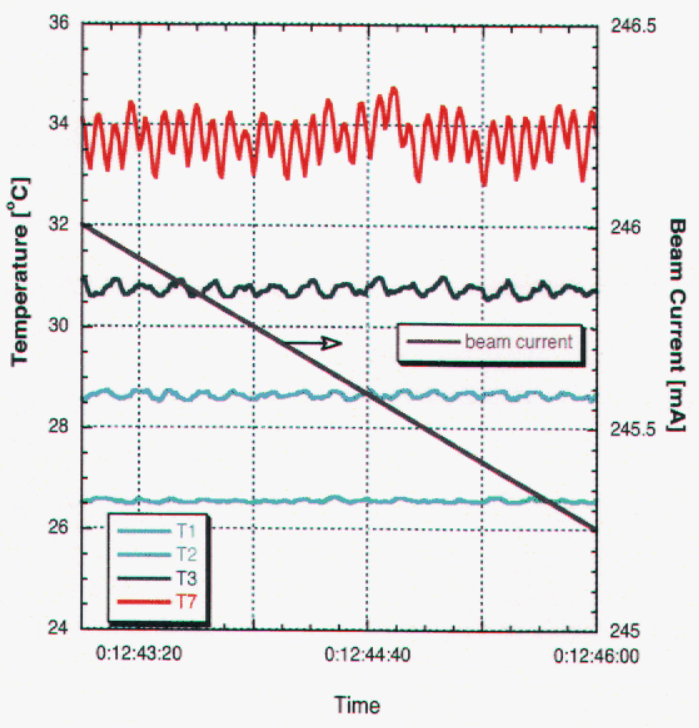

Figure 18 (b). Case 1 details

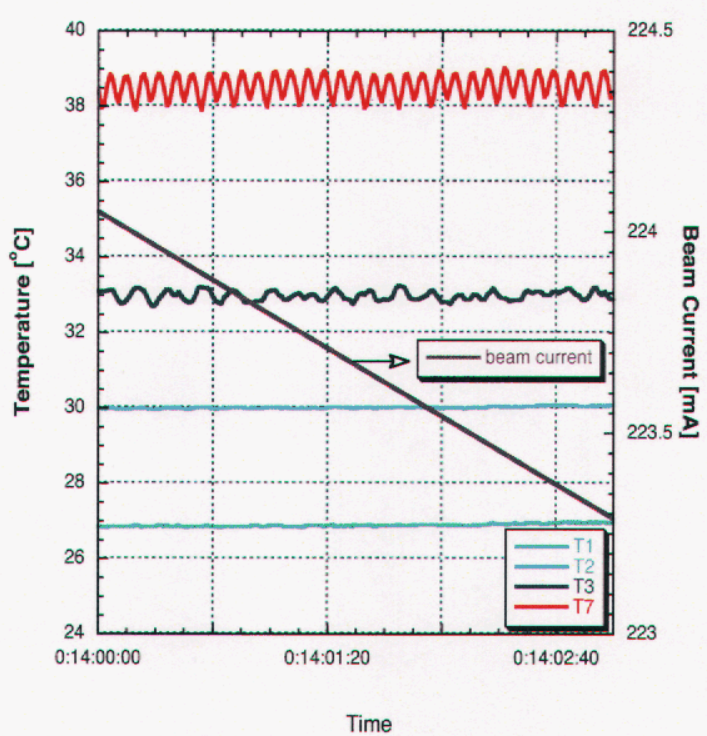

Figure 18 (c). Case 2 details 


\section{Summary and Discussion}

We completed a thermal analysis on a LIGA mask-resist assembly exposed in air at the beam line 3.3.2 of ALS by developing a three-dimensional finite-element model of the assembly. We employed the LIGA exposure software LEX-D (V7.54) to compute the X-ray absorption dose rate in the assembly, which serves as volumetric heat source in the assembly, and we used the commercial software ABAQUS (V6.3) to compute the heat transfer due to this heat source, including thermal conduction inside the assembly and across the material interfaces, natural and forced convection at the assembly top surfaces and thermal radiation in the inner cavity and from the assembly outer surface to the ambient.

The extent of temperature rise on the mask and the resist is our major interest. Heat transfer exchanges and redistributes the heat energy inside the assembly generated by X-ray absorption. The three metal plates become the important thermal conduction paths between the components, and some of their volume is also exposed to either incident or transmitted Xray. Therefore, the thermal analysis needs to be performed on the whole assembly instead of a single mask and a single resist.

Results of integration of interfacial heat fluxes reveal the heat transfer paths in the assembly, as shown in Figure 19. The main path is sequentially from the front plate and mask plate through absorber to the mid plate, then to the substrate and back plate, finally to the water block. Two side paths are directed to the resist including one from the substrate backward to the resist, and the one from the mask plate and the absorber to the cavity air, and then to the resist. These two side paths are major contributors for the resist temperature rise. Results also show forced convection due to nitrogen jets carries away a significant portion of the surface absorbed energy at the mask, while natural convection heat transfer is more than an order-ofmagnitude smaller.

During exposure, the local temperatures are highly non-uniform in the assembly at any instant due to wafer scanning. Therefore, the maximum temperature over all locations of the assembly is more appropriate than an instantaneous temperature profile of the assembly to address the assembly temperature rise. Results of assembly maximum temperatures are comparable with temperature measurements conducted at ALS 3.3.2 beam line for both on and off nitrogen jet cases.

In summary, the temperature rise in the silicon mask plate comes directly from the $\mathrm{X}$-ray absorption, as expected, but nitrogen jets carry away a significant portion of the heat energy. Surprisingly, the temperature rise in PMMA resist results mainly from heat conducted from substrate backward to the resist, and from cavity air forward to the resist, while the contribution from X-ray absorption is only secondary and that from assembly inner cavity radiation is negligibly small. 


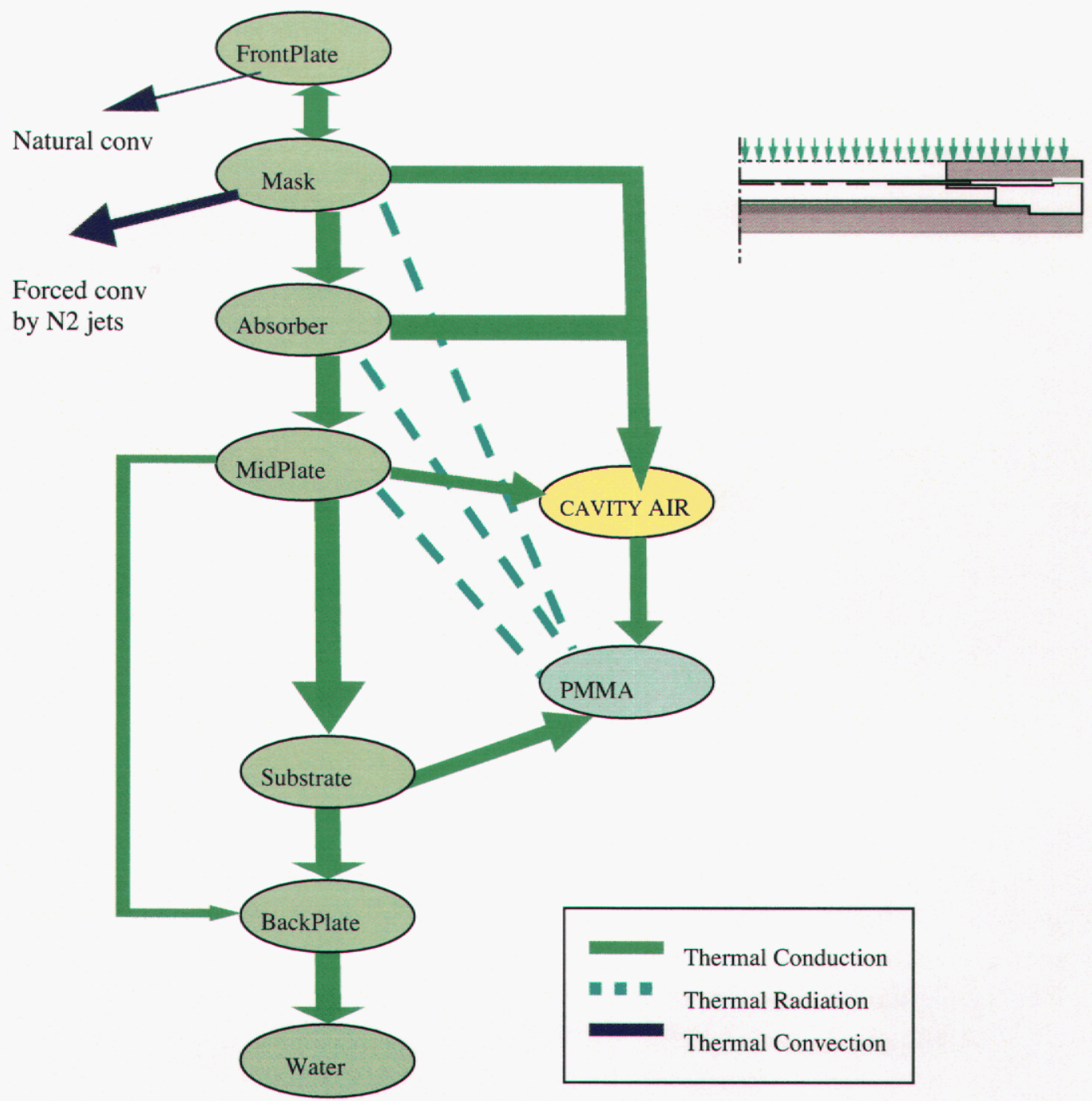

Figure 19. Heat transfer paths in the assembly (radiation at the outer surfaces is not included).

Therefore, an ideal water-cooling block (for example, always at $20^{\circ} \mathrm{C}$ ) attached at the back plate acts as a heat sink that will absorb most of the heat energy along the main conductive path, leaving negligible heat energy directed to the resist from substrate and cavity air so that the resist will stay at its working temperature. Since the current water-cooling did not function properly at the time of the experimental data taken (at room temperature initially and growing higher later), the assembly may be cooled better without the water block. A very long thermal diffusion time scale of the water (results from its lower thermal diffusivity than air (see Table 3 ) and it's large volume) makes the heat transfer very inefficient when the initial water temperature is not low enough, as in the examples. If the front plate touched the mid-plate at the side in the sample instead of leaving a gap as in the current design, there would be another direct thermal conductive path to diffuse heat from the front plate directly through the mid and back plate into the water. 


\section{References}

1. S. K. Griffiths and A. Ting, LEX-D Version 7.54, Sandia LIGA exposure and development software. Nov 2002.

2. ABAQUS Version 6.3, Hibbitt, Karlsson \& Sorensen (west) Inc., 2002.

3. M. Malinowski and C. Hauck, Experiment on temperature measurements of LIGA mask-resist assembly during exposure at ALS 3.3.2 beam line, June 10, 2003.

4. M. Malinowski and C. Hauck, private communication.

5. F. P. Incropera and D. P. Dewitt, Fundamentals of Heat and Mass Transfer, 1985.

6. The Advanced Light Source web pages, Lawrence Berkeley National Laboratory, 
Intentionally left Blank 


\section{Appendix}

Beam line 3.3.2 in ALS

Figure A1 gives the ALS beam lines "clock diagram"[6] showing the storage ring and all beam lines, in which three bend-magnet beam lines for LIGA exposure are located at the lower left corner. The beam energy is $1.894 \mathrm{GeV}$. The beam line 3.3.2 we used in sample exposure is a bend magnet beam line that emits synchrotron $\mathrm{x}$-rays at a horizontal angle of 7 mrad, so at a beam length distance of $18.1 \mathrm{~m}$, the horizontal acceptance is $10.94 \mathrm{~cm}$ (beam width) and the beam height is $1.16 \mathrm{~cm}$.

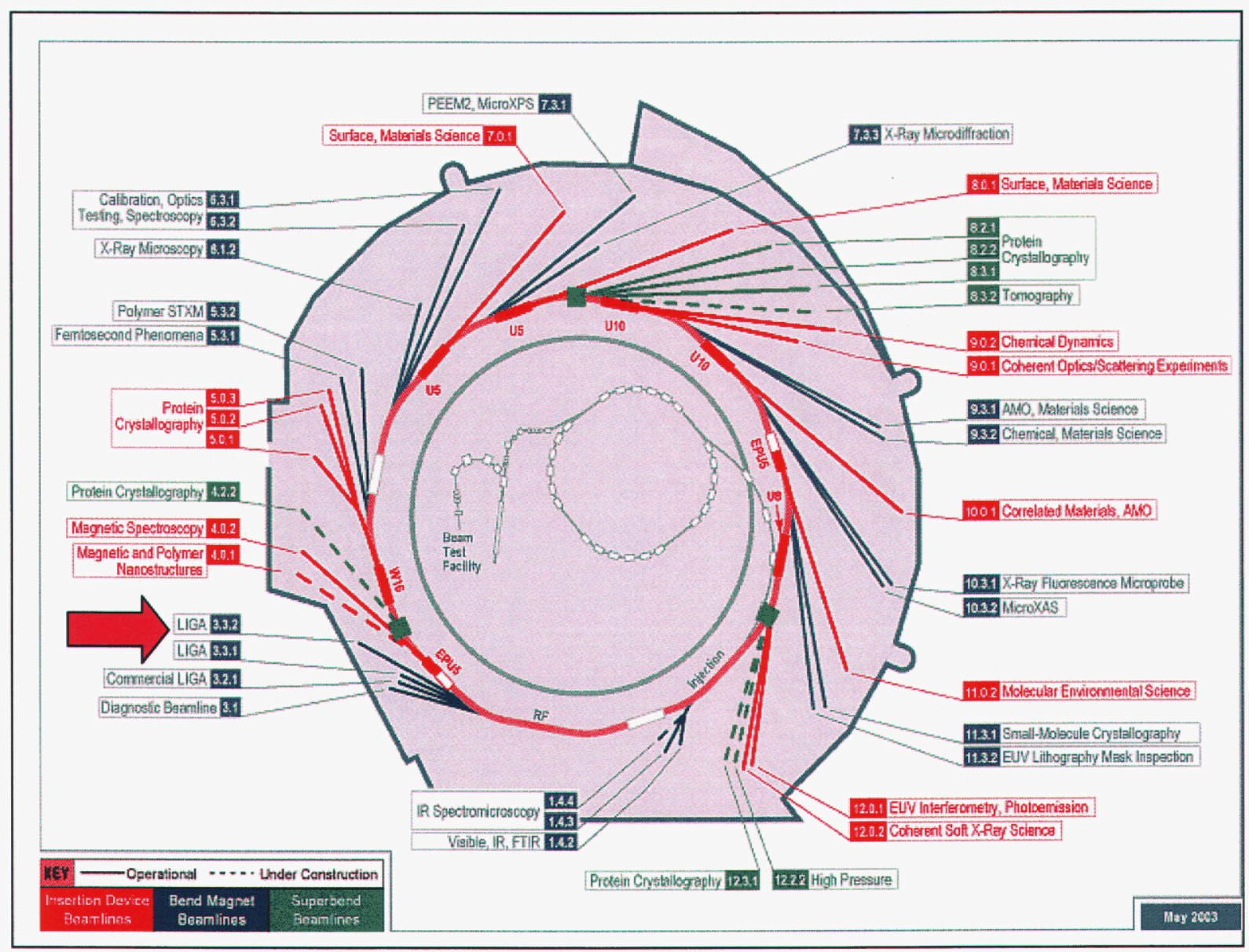

Figure A1. ALS beamline diagram-clock diagram. (Three beam lines LIGA uses are located at the lower left corner. The typical photon flux from the beam line is shown in the small figure on the right).

The power output of beam line 3.3 .2 is about $38.26 \mathrm{~mW} / \mathrm{mr} / \mathrm{mA}$, the photon energy range is around 1 to $20 \mathrm{keV}$, and the peak photon flux occurred approximately at $10 \mathrm{keV}$-photon energy (as sketched in the small sketch). The average operation beam current density is around $280 \mathrm{~mA}$ from a periodic pattern, i.e., beam current decreases

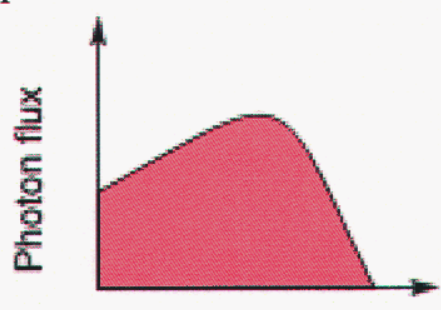

Photon energy exponentially from $400 \mathrm{~mA}$ down to $180 \mathrm{~mA}$ in about eight hours. 
Fig A2 shows a sample beam current in a 24- hour period [6]. The vertical output power profile from the beam is Gaussian. Figure A3 gives a numerical fit of the measured Gaussian profile of synchrotron power output by a photodiode from Beam line 3.3.2, and the fit data [4].

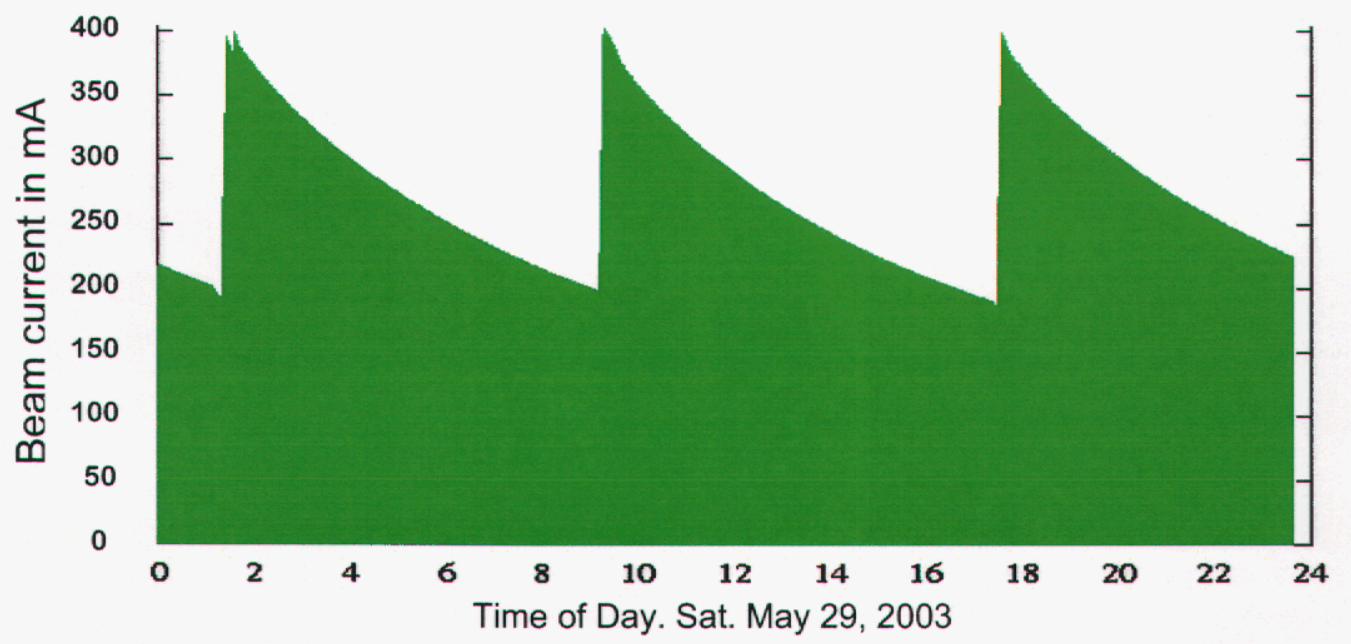

Figure A2. Sample beam current density

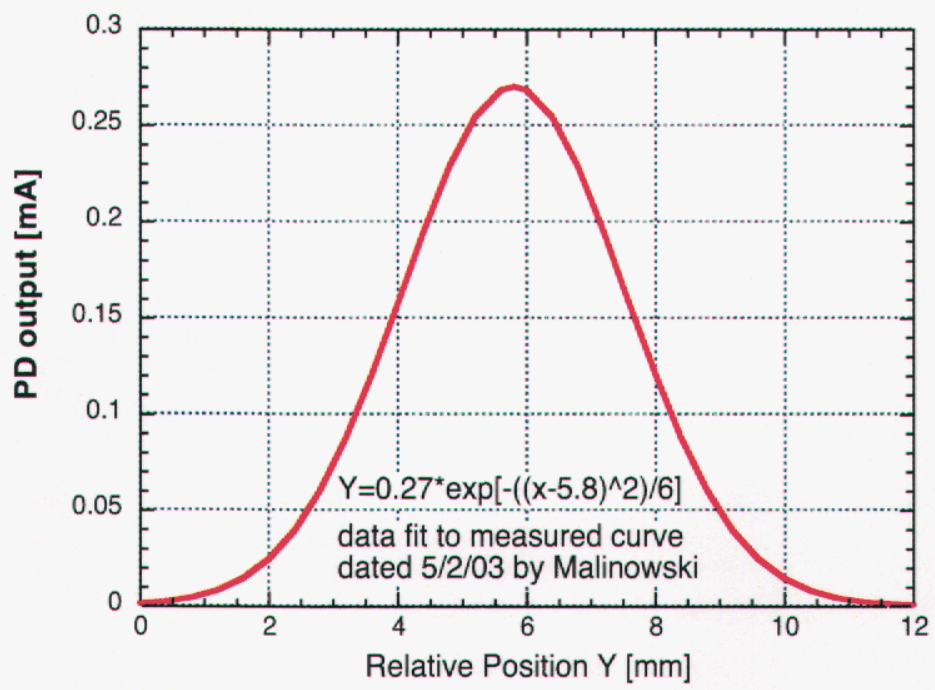

\begin{tabular}{|c|c|c|c|c|c|c|c|}
\hline $\mathrm{X}$ & $\mathrm{Y}$ & $\mathrm{X}$ & $\mathrm{Y}$ & $\mathrm{X}$ & $\mathrm{Y}$ & $\mathrm{X}$ & $\mathrm{Y}$ \\
\hline 0.0 & 0.00099 & 3.2 & 0.08751 & 6.0 & 0.26821 & 9.20 & 0.03932 \\
\hline 0.4 & 0.00209 & 3.6 & 0.12051 & 6.4 & 0.25428 & 9.60 & 0.02433 \\
\hline 0.8 & 0.00418 & 4.0 & 0.15734 & 6.8 & 0.22855 & 10.0 & 0.01427 \\
\hline 1.2 & 0.00794 & 4.4 & 0.19476 & 7.2 & 0.19476 & 10.4 & 0.00794 \\
\hline 1.6 & 0.01427 & 4.8 & 0.22855 & 7.6 & 0.15734 & 10.8 & 0.00419 \\
\hline 2.0 & 0.02433 & 5.2 & 0.25428 & 8.0 & 0.12051 & 11.2 & 0.00209 \\
\hline 2.4 & 0.03932 & 5.6 & 0.26821 & 8.4 & 0.08751 & 11.6 & 0.00099 \\
\hline 2.8 & 0.06025 & 5.8 & 0.27000 & 8.8 & 0.06025 & 12.0 & 0.00045 \\
\hline
\end{tabular}

Figure A3. A numerical fit of the measured Gaussian profile from synchrotron output (measured by Malinowski). 
The assembly is sitting on a linear stage that scans up and down vertically in front of the Xray beam tube inside a hutch, as shown in Figure 3. The modeling adopted a typical scan length of $8.2 \mathrm{~cm}$, which, together with the $10.94 \mathrm{~cm}$ beam width covers a $10.94 \times 8.2 \mathrm{~cm}^{2}$ exposure surface area. In this case, the scanning period is $11.49 \mathrm{~s}$ including the time to turn around (scan speed is about $1.5 \mathrm{~cm} / \mathrm{s}$ ). Figure A4 sketches the scanning time history pattern on the assembly, plotted over time axis and wafer vertical axis.

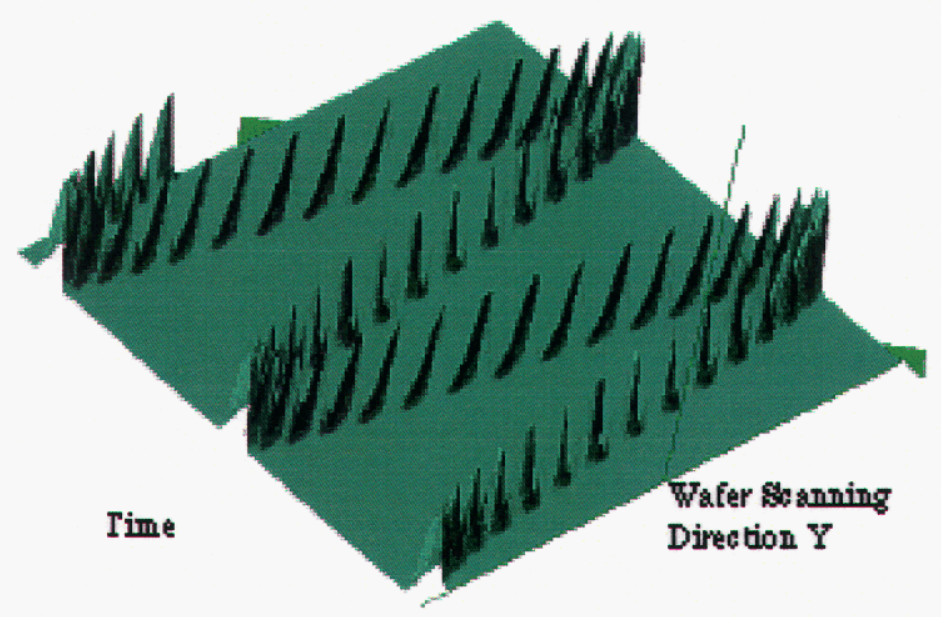

Figure A4. Gaussian train in wafer scanning time history Graph (Only wafer vertical dimension is shown). 
Intentionally Left Blank 


\section{Distribution}

Cheryl A. Hauck

Advance Light Source

Lawrence Berkeley National Laboratory

1 Cyclotron Road MS 80-101

Berkeley, CA 94720

19001 M. E. John, 8000

Attn: D. R. Henson, 8200

R. H. Stulen, 8100

W. J. McLean, 8300

K. E. Washington, 8900

$19401 \quad$ J. M. Goldsmith, 8751

19401 M. A. Hekmaty, 8751

19401 L. L. Hunter, 8751

19401 M. E. Malinowski, 8751

19401 S. Mrowka, 8751

19401 D. M. Skala, 8751

19042 C. D. Moen, 8752

19042 G. H. Evans, 8752

19042 S. K. Griffiths, 8350

19042 W. G. Houf, 8752

19042 R. S. Larson, 8752

19042 R. H. Nilson, 8752

19042 M. P. Kanouff, 8752

19042 B. M. Rush, 8752

109042 A. Ting, 8752

19042 W. S. Winters, 8752

19401 G. Aigeldinger, 8753

19401 D. R. Boehme, 8753

19401 J. T. Hachman, 8753

19401 T. I. Wallow, 8753

$19401 \quad$ P. C. Y. Yang, 8753

19401 A. M. Morales, 8762

19405 J. M. Hruby, 8700

19405 K. L. Wilson, 8770

Attn: J. C. F. Wang, 8773

D. Kwon, 8774

19404 G. D. Kubiak, 8750

Attn: P. A. Spence, 8754

199161 W. R. Even, 8760

19161 Attn: D. L. Medlin, 8761

T. J. Shepodd, 8762

E. P. Chen, 8763 
39017 Central Technical Files, 8945-1

10899 Technical Library, 9616

19021 Classification Office, 8511/Technical Library, MS 0899, 9616

DOE/OSTI via URL

LIBRARY DOCUMENT

DO NOT DESTROY

RETURN TO

LIBRARY VAULT 